\title{
Invited Review: Perspectives on the Basis of the Rheology and Texture Properties of Cheese
}

\author{
J. A. Lucey, ${ }^{*}$ M. E. Johnson, $†$ and D. S. Horne‡ \\ *Department of Food Science, \\ †Wisconsin Center for Dairy Research \\ University of Wisconsin-Madison, 53706 \\ $\ddagger$ Charis Food Research, Hannah Research Park \\ Ayr, KA6 5HL, Scotland, UK
}

\begin{abstract}
Physical and chemical properties of cheese, such as texture, color, melt, and stretch, are primarily determined by the interaction of casein $(\mathrm{CN})$ molecules. This review will discuss CN chemistry, how it is influenced by the cheese-making process, and how it impinges on the final product, cheese. We attempt to demonstrate that the application of principles governing the molecular interactions of $\mathrm{CN}$ can be useful in understanding the many physical and chemical properties of cheese and, in turn, how this can be used by the cheesemaker to produce the desired cheese. The physical properties of cheese (as well as flavor) are influenced by a number of factors including: milk composition; milk quality; temperature; the rate and extent of acidification by the starter bacteria; the $\mathrm{pH}$ history of cheese; the concentration of Ca salts (proportions of soluble and insoluble forms); extent and type of proteolysis, and other ripening reactions. Our hypothesis is that these factors also control and modify the nature and strength of $\mathrm{CN}$ interactions. The approach behind the recently proposed dual-binding model for the structure and stability of $\mathrm{CN}$ micelles is used as a framework to understand the physical and chemical properties of cheese.
\end{abstract}

(Key words: casein, milk salts, cheese structure and texture, functional properties)

Abbreviation key: $\mathbf{C C P}=$ colloidal Ca phosphate, $\mathbf{G}^{*}$ $=$ complex modulus, $\mathbf{G}^{\prime}=$ storage or elastic modulus, $\mathbf{G}^{\prime \prime}$ $=$ loss or viscous modulus, $\tan \delta=$ loss tangent, TPA = texture profile analysis.

\section{INTRODUCTION}

The initial steps of cheese making involve the coagulation of $\mathrm{CN}$ micelles via three possible methods: limited

Received December 16, 2002.

Accepted February 6, 2003.

Corresponding author: J. A. Lucey; e-mail: jalucey@facstaff.wisc. edu. proteolysis (using rennet or other coagulants), acidification (starter culture or addition of acids) and heat, or combinations of these three methods. Various curd handling steps convert this weak gel network into a fresh "green" curd. The art or science of cheese making is all about managing five key factors; milk composition, rate and extent of acid development, moisture content, curd manipulation, and maturation conditions. Whereas these practices, developed over centuries, have resulted in many studies on cheese that have verified (and expanded) the prior art of cheese making, it is becoming increasingly recognized by researchers that there is a need to understand cheese making at a molecular level. An understanding of CN chemistry will allow cheese technologists to build models to explain the various physical and chemical attributes of cheese and perhaps develop novel approaches to cheese making and control of physical characteristics of cheese.

The physical properties of cheese (i.e., body/texture, melt/stretch, and color) are influenced by initial cheesemilk composition, manufacturing procedures, and maturation conditions. Two of the most important factors influencing these properties are the condition of the $\mathrm{CN}$ particles in cheese (e.g., interactions between and within molecules, as well as the amount of $\mathrm{Ca}$ associated with these particles) and the extent of proteolysis. These are in turn influenced by various environmental conditions such as $\mathrm{pH}$ development, temperature, and ionic strength. Therefore, how individual CN molecules, or aggregates of many $\mathrm{CN}$ molecules interact, is vital in understanding the physical and chemical properties of cheese. For example, it has long been recognized that $\mathrm{pH}$, temperature, Ca levels, and proteolysis (both during manufacture and ripening) play an important role in defining physical properties of cheese, but a unifying principle for these observations is needed.

The protein matrix in cheese originates from small CN particles held together by various (physical) forces throughout which are dispersed moisture and fat globules (Luyten et al., 1991). The forces and interactions that lead to and contribute to the formation and stabil- 
ity of CN micelles are important in defining the functional properties of cheeses. Although the $\mathrm{CN}$ molecules have been translated into a new environment by the cheese-making process, we speculate that the influences of the main features of this environment (high solids, close packing, low $\mathrm{pH}$, high salt) on cheese functional properties can all be rationalized in terms of the basic properties of the $\mathrm{CN}$ themselves. It is likely that the interactions between $\mathrm{CN}$ molecules in micelles and in cheese are modulated by electrostatic and hydrophobic interactions. Covalent bonds are important in acidheat coagulated cheeses, such as ricotta and quarg, but are only of minor importance in most natural cheeses. The strength or contribution of each type of interaction is governed by the residual charge on the $\mathrm{CN}$ molecule (which is directly influenced by $\mathrm{pH}$, the ionic strength, and $\mathrm{Ca}$ binding), the type of $\mathrm{CN}$, and the temperature of the cheese.

In the United States, a high proportion of all cheese (both natural and processed) ends up being used as an ingredient (e.g., on pizza, cheeseburgers, lasagna, cheese sticks, and breads). In most of these applications (e.g., as a pizza topping), physical and rheological characteristics of cheese are often more important than flavor attributes. The popularity of processed cheese in the United States is primarily due to its use as a functional ingredient (e.g., slices on cheeseburgers that are sold in fast food establishments). Processed cheese is a good example of a cheese that must possess well-defined functionality requirements. These include the ability to form individual slices and melt in a very specific manner. For natural types, there are additional functional requirements such as the ability to machine, shred, slice, dice, cube, melt, flow, soften, and stretch. There have been numerous studies on the effects of various cheese-making parameters (e.g., fat content, coagulant concentration, starter culture type, cooking temperature, storage time) on functional characteristics of single cheese varieties, such as Cheddar and Mozzarella. However, the overriding mechanisms or some unifying principles that are responsible for this multitude of functional attributes have not been addressed. In this article we will present an overall conceptual framework for these phenomena based on the dual-binding model (Horne, 1998) for the structure and stability of CN micelles.

\section{CHEESE-MAKING PROCESS}

\section{Casein Properties}

The first stage in the manufacture of cheese involves the destabilization of the $\mathrm{CN}$ micelles to bring them together into the network that is the cheese curd (Johnson and Law, 1999). The CN micelles are the colloidally dispersed aggregates of the $\mathrm{CN}$ proteins together with mineral $\mathrm{Ca}$ and phosphate called colloidal Ca phosphate (CCP). Physically they are the entities that scatter light and confer on milk its whiteness and opacity; biologically they are the transporters of a major portion of the nutrients and minerals essential to the growth and nourishment of the neonate.

The CN are a family of phosphoproteins. In bovine milk, the milk of major commercial importance, the family consists of four members, designated $\alpha_{\mathrm{s} 1^{-}}, \alpha_{\mathrm{s} 2^{-}}$, $\beta$, and $\kappa$-CN. Together they constitute about $80 \%$ of bovine milk proteins and are found in the proportions 4:1:4:1, respectively (Walstra and van Vliet, 1986). As well as being differentiated by their amino acid sequences, the $\mathrm{CN}$ are distinguished by their number and distribution of phosphoseryl residues and their sensitivity to precipitation by ionic Ca. $\alpha_{\mathrm{s}^{-}}, \alpha_{\mathrm{s} 2^{-}}$, and $\beta$-Caseins are multi-phosphorylated and these are found in groups or clusters. $\kappa$-Casein has only one phosphoseryl residue.

Controversy still exists over the level of secondary structure present in the CN. Previously, much of this was designated random coil in line with the open, highly hydrated state presented by the molecules in solution. Current opinion suggests that parts of $\beta$ - and $\kappa-\mathrm{CN}$ might adopt the polyproline II-helix structural motif (Farrell et al., 2001; Syme et al., 2002). From the point of view of their self-association and micellar assembly, the amphiphilicity of the CN may play a more crucial role than recognizable secondary structural elements. The clusters of the phosphoseryl residues are surrounded by polar and charged residues, making these regions very hydrophilic. However, other regions of these molecules have a high concentration of hydrophobic residues conferring on the molecules almost a block copolymer structure. Thus, the N-terminal peptide of $\beta$-CN with the phosphoseryl cluster is very hydrophilic and the C-terminal is hydrophobic. The behavior of this protein on adsorption at a hydrophobic interface reflects this segregation, with the hydrophobic C-terminus adsorbing strongly to this surface and the hydrophilic $\mathrm{N}$-terminal tail sticking out into solution (Horne and Leaver, 1995). Ample experimental evidence from dynamic light scattering, neutron reflectivity, enzyme proteolysis, and surface force measurements confirm this view. Further support comes from self-consistent field calculations to determine the segment density of a polymer model of $\beta$-CN normal to the adsorbing surface (Dickinson et al., 1997a, 1997b). Similar calculations carried out on $\alpha_{\mathrm{s} 1}-\mathrm{CN}$ suggest that this protein can be divided into three blocks, a hydrophobic $\mathrm{N}$-terminal region, a hydrophilic central loop containing the phosphoseryl clusters that extend out into the aqueous phase on adsorption and a hydrophobic C-terminal pep- 
tide. Such structures reflect the general distribution of hydrophilic and hydrophobic residues along these CN protein sequences. With such knowledge, a block polymer structure can be drawn for $\alpha_{\mathrm{s}^{2}} \mathrm{CN}$ depicting it as having four blocks-a hydrophilic N-terminal tail with a phosphoseryl cluster, followed by a hydrophobic train, a hydrophilic loop containing further clusters of phosphoseryl residues and finally a second hydrophobic train at its $\mathrm{C}$-terminus. $\kappa$-Casein is similarly the mirror image of $\beta$-CN with a hydrophilic C-terminus, the caseinomacropeptide cleaved by chymosin, and a hydrophobic N-terminal below the Phe ${ }_{105}-$ Met $_{106}$ bond. Importantly, however, the macropeptide has no phosphoseryl cluster.

From these structures, Horne (1998) devised a polymerization scheme (dual-binding model) for the assembly of CN micelles. Cross-linking of the molecules was envisaged as proceeding via two routes, hydrophobic interaction between groups on different molecules forming one pathway, with more than two molecules possibly joining at such junctions, and a second pathway where chain extension is through a CCP nanocluster acting as a neutralizing bridge between two negatively charged phosphoseryl clusters on separate molecules of $\alpha_{\mathrm{s1}^{-}}, \alpha_{\mathrm{s} 2^{-}}$, or $\beta$-CN. In practice, more than two CN molecules could be involved with any one Ca phosphate nanocluster. If the $\mathrm{CN}$ molecule is $\beta$ - $\mathrm{CN}$, then further extension of this chain is through a hydrophobic linkage. Both routes permit branching and hence lead to a three-dimensional network. $\kappa$-Casein, however, can link only to a hydrophobic residue on another CN molecule. Because it has no phosphoseryl cluster to permit further extension, the polymer chain ends there. No further growth occurs beyond this point. This occurs for each growing chain and hence the proportion of $\kappa$ $\mathrm{CN}$ limits the micelle size. In consequence, the $\kappa$-CN acquires an external surface position where it acts as a steric stabilizer.

In devising this mechanism for micellar assembly and structure, no new features are ascribed to the CN molecules. The ability to bond, the strength of those bonds is the result of a localized balance of hydrophobic interaction and electrostatic repulsion. Decreasing hydrophobic interaction by lowering temperature or increasing electrostatic repulsion by dissolving out $\mathrm{Ca}$ phosphate but maintaining $\mathrm{pH}$, disrupts one bonding pathway, weakens also those adjacent bonds and causes (partial) disintegration of the micelle. These are the concepts and ideas, which we now suggest still operate in a cheese environment and which we now attempt to use in a rationalization of cheese functional and physical properties.

\section{Curd Formation}

Most natural cheese types are made by the use of rennet enzyme to coagulate the $\mathrm{CN}$ micelles in milk and the addition of starter culture to produce acid (some are made by direct acid addition). Rennet-altered CN micelles are susceptible to aggregation due to the reduction in steric and charge repulsion (between particles) caused by the loss of the macropeptide from $\kappa$-CN. The enzymatic coagulation of milk has been extensively reviewed (Dalgleish, 1993; Green and Grandison, 1993; Hyslop, 2003). Rennet-altered micelles aggregate into clusters and chains that eventually form a system-spanning network that surrounds the fat globules. Serum is also trapped in the spaces (pores) between and within these aggregates. The rheological properties of rennetinduced gels have been extensively investigated (Dejmek, 1987; Zoon et al., 1988a, 1988b). The evolution in the rheological properties of the gel network can be monitored using dynamic low amplitude oscillation. This rheological technique indicates that after an initial lag period, where hydrolysis of $\kappa$-CN is occurring, there is a rapid increase in gel stiffness, which starts to flatten after a period of time, depending on the concentration of enzyme used.

Gel formation is greatly influenced by $\mathrm{pH}$, Ca concentration, protein content, and temperature (Lomholt and Qvist, 1999; Lucey, 2002). In cheese making, gelation $\mathrm{pH}$ varies due to the action of starter culture, preripening of the cheesemilk, or addition of acid or acidulants. Calcium concentration varies in practice due to changes in milk composition, acid development, and the addition of $\mathrm{CaCl}_{2}$. Gelation temperature is selected by the cheesemakers based on cheese type and experience.

When the gel has attained sufficient firmness, which is traditionally determined subjectively by the cheesemaker, it is cut with knives. In practice, if the curd is cut when it is very soft, the moisture content of the resulting cheese is lower (Johnson and Law, 1999; Johnson et al., 2001). If the gel is left for a longer time before cutting, the moisture content of the cheese is higher. Presumably, this change in the moisture content is a reflection of the extent of bonding between and within CN particles, which increases with time. Additional events, such as fusion of particles, rearrangement processes, and further incorporation of micelles into the network, all contribute to the growth in gel strength. If milk is preacidified or ripened with starter culture, then the $\mathrm{pH}$ at renneting is lower than the natural $\mathrm{pH}$ of milk. The lower $\mathrm{pH}$ results in solubilization of CCP but little dissociation of $\mathrm{CN}$ (at least at the temperatures normally used for renneting most rennet-induced cheeses). Gelation proceeds faster due to the reduction in $\mathrm{pH}$ primarily due to the reduction in charge repulsion 
between micelles and accelerated rennet activity. Gel stiffness increases with a reduction in $\mathrm{pH}$ up to a maximum at $\mathrm{pH} 6.0$ to 6.2 ; at lower $\mathrm{pH}$ values the stiffness decreases.

Applying the Horne model to gelation, we can view this as occurring due to the reduction in electrostatic repulsion caused by the hydrolysis of the macropeptide and the interaction balance between $\mathrm{CN}$ molecules being shifted towards hydrophobic attraction between rennet-altered micelles. Steric stabilization also plays a significant role, but the drop in zeta potential indicates that electrostatic repulsion and that of charge decrease-possibly due to its influence on the effectiveness or range of the steric component-will become more significant as the $\mathrm{pH}$ is decreased and the electrostatic component is removed. The reduction in firmness at low $\mathrm{pH}$ values $(\leq 6)$ can be viewed as being caused by the solubilization of CCP crosslinks and the concomitant increase in electrostatic repulsion between the exposed phosphoserine residues (Lucey, 2002). Between $\mathrm{pH} 6.6$ and $~ 6.0$, the amount of CCP (crosslinks) that is dissolved is still low and firmness probably increases due to the large decrease in electrostatic repulsion with the reduction in $\mathrm{pH}$. This approach is supported by the observation that reducing the CCP content of milk while maintaining a high $\mathrm{pH}$ value and a constant $\mathrm{Ca}^{2+}$ activity (so removing CCP crosslinks at a constant $\mathrm{pH}$ ) reduced the rennet coagulability of milk (Shalabi and Fox, 1982; Udabage et al., 2001). The Horne model has recently been successfully applied to explain several other properties of various types of milk gels (Lucey, 2002).

In ricotta and queso blanco style cheeses, milk is heated to $\sim 80$ to $85^{\circ} \mathrm{C}$. Acidulants (e.g., acetic, lactic, or citric) are added to the hot milk to bring the $\mathrm{pH}$ to $\sim 5.9$ to 5.4. Flocculation of $\mathrm{CN}$ occurs rapidly under these conditions, before it is mechanically dewheyed. In these cheeses, both $\mathrm{CN}$ and $\beta$-lactoglobulin jointly precipitate (forming the curd structure). In cottage cheese, milk is incubated with culture $\left(\sim 22\right.$ to $\left.35^{\circ} \mathrm{C}\right)$, and the length of time before cutting varies from 5 to $16 \mathrm{~h}$. A low level of rennet $(0.1$ to $5 \mathrm{ml}$ of standard, single-strength rennet per $1000 \mathrm{~L}$ of milk) may be added in cottage cheese, which helps to form a gel suitable for cutting, and aids in moisture expulsion of large curd cottage cheese. Rennet is often added after some acidity has been developed by the starter culture (e.g., after 1 to $2 \mathrm{~h}$ ). When rennet is added, the gel is ready to be cut at a higher $\mathrm{pH}$ (e.g., 4.8) than in its absence (e.g., 4.6). The presence of denatured whey proteins in acidinduced $\mathrm{CN}$ gels made from heated milk results in gelation occurring at higher $\mathrm{pH}$ values due to the higher isoelectric point of $\beta$-lactoglobulin (Lucey, 2002). Gelation can be viewed as occurring when there is an excess hydrophobic attraction over electrostatic repulsion and this occurs earlier when a little rennet is added in cottage cheese making because rennet removes the negatively charged macropeptide.

\section{Curd Handling}

In rennet-induced gels, most of the serum is lost as whey after the coagulum is cut, but some remains between and within CN aggregates. Most cheeses are cooked, i.e., heated to temperatures higher than those used for gelation, mainly as a means of increasing the syneresis of the curd particles. For cheeses in which a low moisture content is required, the coagulum is cut into small curd particles using fine knives and a high cook temperature is also used. (Rennet-induced gels are used when low moisture cheeses are desired as cheeses made by acid coagulation have very high moisture contents, e.g., quarg, possibly due to less protein rearrangements of the gel network.) After cutting, the curd particles are continuously stirred during the cooking and holding stage in the vat, and the collisions between particles also increase syneresis. After whey drainage, the curd particles start to fuse together unless fusion is prevented by stirring in the vat (i.e., stirredcurd type cheese). Fusion of particles becomes more obvious at $\mathrm{pH}$ values $<6.0$ and corresponds to the "cheddaring" stage in traditional Cheddar cheese manufacture. Along with increased fusion, there is also the development of a fibrous or chicken breast type of structure at $\mathrm{pH}<5.8$, which is related to solubilization of CCP crosslinks. During the later stages of cheese making there is the concomitant expulsion of additional moisture and an increase in the firmness of the curd. The application of pressure (either in a tower in Cheddar manufacture or in a Casomatic in Gouda manufacture) also assists in moisture expulsion.

In pasta-filata type cheeses, the curd is subjected to a stretching process in hot water $\left(>70^{\circ} \mathrm{C}\right)$. Cheesemakers subjectively decide when the curd is suitable for stretching. This point depends on many factors including the composition of the cheese and method used for acidification. The $\mathrm{pH}$ can range from 5.6 in directly acidified Mozzarella (depends on type of acid used) to $\sim 5.1$ to 5.2 in low-moisture part-skim Mozzarella to $\sim 5.0$ in very low fat Mozzarella. The cooking and stretching process helps to confer a plastic appearance to the curd and promotes the formation of a fibrous structure. The heat treatment reduces the amount of residual rennet activity in the curd, which decreases the amount of primary proteolysis that occurs during ripening.

In Cheddar and other dry-salted cheeses, the curd is kept granular by stirring (stirred-curd) or matted and later milled into small pieces before the application of 
dry salt. The pieces of curd are thoroughly mixed before they are hooped and pressed. The pressure encourages the formation of bonds between these curd pieces, although junction zones are still partly visible in aged cheese. One consequence of forming curd pieces by milling (and then salt addition) is that the continuity of the cheese matrix is much reduced compared with the original gel network.

Most other cheeses are salted by immersion of the cheese block into saturated brine for a length of time that is dictated by the type of cheese, and the shape and size of the block. In brine salted cheeses there is diffusion of salt into the cheese and outward migration of water. Cheese composition (and proteolysis) varies from the inside to the outside of the block, and this is reflected in differences in textural and functional properties within the cheese block.

\section{FUNCTIONAL PROPERTIES OF CHEESE}

\section{Introduction to Cheese Rheology and Texture}

In physical terms, cheese is a viscoelastic material and all textural characteristics are a weighted combination of measurable rheological and fracture (mechanical) properties. A material, such as cheese, is considered viscoelastic if during (and after) deformation part of the mechanical energy supplied to it is stored in the material (elastic part) and part is dissipated (viscous part). The ratio of dissipated to stored energy depends on the time scale of the deformation and the consequence is that the material response is time-dependent. Moreover, energy dissipation may cause (part of) the deformation to be long lasting or permanent. The viscoelastic properties of foods can be determined by dynamic low amplitude oscillation to measure the elastic or storage modulus $\left(\mathbf{G}^{\prime}\right)$, viscous or loss modulus $\left(\mathbf{G}^{\prime \prime}\right)$, complex modulus $\left(\mathbf{G}^{*}\right)$, and loss tangent $(\tan \delta)$, which is the ratio of viscous to elastic moduli $\left(\mathrm{G}^{\prime \prime} / \mathrm{G}^{\prime}\right)$ (Steffe, 1996).

As cheese is a viscoelastic material, time plays an important role in its mechanical behavior influencing the results obtained in rheological experiments as well as sensory attributes. The timescale of an experiment is the time that a stress of a certain magnitude and direction acts on a material (van Vliet, 1999). For many viscoelastic foods the reaction due to a stress may be relatively more elastic or viscous depending on the timescale of the stress application. There are numerous occasions when this aspect is important in cheese making, e.g., cutting the initial coagulum, formation of splits or cracks in eye cheeses, and stretching curd for pasta-filata types. If the soft initial coagulum is cut at high speed, then excessive damage and a lot of fines are produced; a slower cutting speed allows the knives to cut cleanly through the gel. When performing a simple fork test to assess the stretch properties of cheese on pizza, it is subjective as to how much stretch one can obtain because, if the cheese is pulled or lifted rapidly, it does not stretch much but easily breaks, in contrast to the situation in which the cheese is stretched slowly. In another example, over short timescales, Camembert cheese behaves elastically -it can be cut with a knifewhereas over long timescales it flows, even at refrigeration temperatures (van Vliet, 1999).

The origin of the time-dependent behavior of foods lies in the structure. The structure of most food materials is not static; the majority of bonds between structural elements are not permanent. These bonds will occasionally break and reform due to Brownian motion. The rate by which these processes proceed may vary greatly and is accelerated by the application of a stress (e.g., stretching of cheese), which is the introduction of mechanical energy. For ideal elastic materials this rate is effectively zero. In a liquid, bonds are also present between structural elements, but they break and reform much faster than the timescale of the experiment, and all energy supplied will be immediately dissipated as heat (van Vliet, 1999). In viscoelastic materials, to which a stress is applied, an intermediate behavior occurs because bond lifetime is of the same order of magnitude as the duration of the experiment.

During nonlinear deformation, bonds between structural elements are broken that do not reform during the experiment, and the application of still larger stresses causes the sample to fracture, i.e., all bonds within a certain plane are broken (Walstra and van Vliet, 1982). The stress at which fracture occurs depends on the deformation rate (a higher rate necessitates a higher stress) (Walstra and van Vliet, 1982). At higher deformation rates, there is less time for relaxation of the stresses generated; a similar phenomenon occurs in dynamic oscillation with the use of high frequencies. The large deformation properties of cheese can be determined by various (fundamental and empirical) approaches including uniaxial compression, texture profile analysis, and torsion (fracture) (van Vliet, 1991a). Large deformation and fracture properties strongly depend on the size of the largest inhomogeneities or "weak spots" in the cheese matrix (Luyten and van Vliet, 1996). The development of cracks and their growth (fracture initiation and propagation) depends on various factors including the energy required to overcome the adhesive or cohesive stresses in the material, how the stored energy (due to the application of the stress) is released, and the viscoelasticity of the cheese (Luyten and van Vliet, 1996; Noël et al., 1999). Inhomogeneities in cheese could include curd junctions, mechanical openings, cracks, and eyes. 
The number, strength, and type of bonds between $\mathrm{CN}$ molecules constitute the basis of the rheological properties of cheese. The spatial arrangement of these bonds will impact the rheological properties; however, presently there is little even qualitative knowledge on this aspect. One possible avenue of tackling this problem might be to consider a mean-field approach, i.e., considering an isolated molecule in an averaged energy situation. Alternatively, many rheological tests, such as dynamic oscillation, operate within the so-called linear viscoelastic region, where some sort of equilibrium is maintained in which stretched bonds revert to their original state. As outlined above, two factors are important in these tests: The magnitude of the stress and the rate at which this stress is applied (i.e., frequency of the oscillation cycle). Some bonds are weak and may be broken by the application of this stress. The reformation reaction occurs at a finite rate determined by the interaction energy profile. The inverse of this rate is the relaxation time, but because there are so many bonds of different strengths and in different environments in the system it becomes a relaxation spectrum. This relaxation spectrum is defined by the spread of bond strengths. By considering the role of environmental and other factors on these interactions between the $\mathrm{CN}$, much can be said of their impact on the textural properties of the cheese.

Several excellent reviews on the texture, rheology, and fracture properties of cheese (IDF, 1991; Prentice et al., 1993; Fox et al., 2000) set the scene.

\section{Body and Texture}

In cheese grading or judging, the physical properties are commonly identified in the terms "body" and "texture". By convention, in the dairy industry the term "body" denotes the consistency of the product (e.g., firmness, softness, cohesiveness, rubberiness, elasticity, plasticity, pastiness, brittleness, curdiness, crumbliness), whereas "texture" refers to the relative number, type, and size of openings that can be observed visually (e.g., close, open, gassy, slit-openings, mechanical openness) or by the sense of touch (as in mealy/ grainy) to reveal internal particles (Van Slyke and Price, 1979; Bodyfelt et al., 1988). Confusingly, all the terms listed above for the "body" of cheese are widely used outside the dairy industry to describe the textural, rheological, and fracture properties of foods (Bourne, 1982). Van Vliet (1991b) reported precise definitions of the recommended terminology to be used to describe the textural, rheological, and fracture properties of cheese. In this article, we will use the terminology proposed by Van Vliet (1991b). Attempts to develop direct relationships between these empirical or subjective tex- tural attributes with fundamental rheological and fracture properties have met with limited success (Peleg, 1980; Jack et al., 1993).

Different cheese varieties have a wide range of textural characteristics, and these also greatly change with aging due to proteolysis, moisture loss, salt uptake, $\mathrm{pH}$ change, and the slow dissolution of residual $\mathrm{Ca}$ associated with $\mathrm{CN}$ particles. Cheese composition (i.e., moisture, protein, fat, $\mathrm{NaCl}$, milk salts, and $\mathrm{pH}$ ) has a major impact on the body and texture of cheeses. Cheese composition is mainly controlled by the initial composition of the cheesemilk (which is modified by the method used for milk standardization) and the manufacturing protocols (e.g., $\mathrm{pH}$ at renneting and draining, size of curd particles, cooking temperature, method of salting) used for cheese making. Factors such as species and breed of animal, stage of lactation, and seasonality, can all affect the initial milk composition and alter the texture of cheese. Traditional standardization of milk usually means maintaining a particular $\mathrm{CN}$ to fat ratio by cream addition/removal or addition of skim milk. This does not mean that cheese is always made from totally uniform milk as the total contents of $\mathrm{CN}$, minerals, fat, and lactose can still vary with this procedure.

Another important textural property is proper eye development in Emmental or Gouda cheese (i.e., size, spacing, and number). For this to occur, the curd should be pliable enough so that as gas is being produced slowly at the appropriate time (e.g., in the hot room stage for Emmental) a smooth eye is formed rather than a crack or split, which can occur if excessive gas is produced too rapidly or if fracture occurs at a relatively small deformation ("short cheese") (Zoon and Allersma, 1996; Noël et al., 1999). The main factors influencing the deformation at fracture are $\mathrm{pH}$ (and the amount of $\mathrm{Ca}$ associated with the $\mathrm{CN}$ ) with cracks more likely to occur in Gouda or Emmental cheese if the $\mathrm{pH}$ is below 5.15 and if gas is produced at a later stage of maturation (because proteolysis reduces the fracture strain) (Akkerman et al., 1989; Luyten et al., 1991; Luyten and van Vliet, 1996; Zoon and Allersma, 1996).

\section{Melt, Stretch, and Other Related Characteristics}

When cheese is heated, many interrelated changes can be readily observed such as melt, flow, softening, and stretch. For some cheeses, changes can even occur at relatively low temperatures (e.g., over-ripe Camembert), but more commonly a reasonable temperature rise $\left(>40^{\circ} \mathrm{C}\right)$ is required. From a physical point of view, a substance melts when it is transformed from a "solidlike" to a "liquid-like" state. Fat is the only solid in cheese that truly melts (in the usual temperature range used for pizza baking types of applications). Milk fat is 
composed of different triglycerides, each with a different melting temperature. Some fractions will be molten at refrigerator temperatures, while other fractions will still be solid at room temperature, but overall, milk fat is completely liquid at about $40^{\circ} \mathrm{C}$ (Walstra and Jenness, 1984). The other solids in cheese are CN and some serum proteins (which are present in the serum phase of cheese). Proteins do not melt, but their interactions with each other can change to produce an effect that we call melt.

By convention, melt (as it applies to cheese), is the ability of the cheese to flow and spread as well as the loss of (visual) integrity of the individual cheese shreds. But what does it mean when we say that a cheese melts? Just as there are two components to the complex modulus, the melt and flow behavior can be categorized by softening and flow. Softening can be related to the loss of elasticity, which occurs when all cheeses are heated. Flow may occur when the viscous modulus becomes greater than the elastic modulus. In practice, cheese softens before it flows, but cheese does not have to flow just because it softens. An example of this phenomenon is breaded cheese sticks for frying. The cheese is made specifically to soften but not flow. Of course, if sufficient pressure or thermal energy is applied to the softened cheese, it will flow. Most test methods for assessing melt use gravity (as on pizza or a sample in an oven) to determine the rate and extent of flow as cheese is heated, and so the resultant of the two components, softening and flow, are integrated into the measurement outcome. Much of the cheese industry still assesses melt characteristics by the performance of cheese when baked on pizza. There have been several reviews on the various instrumental test methods used to investigate the physical properties of cheese, especially melt (Park et al., 1984; Ruegg et al., 1991; Olson et al., 1996). Recently, there have been several developments in measuring the melt and flow of cheese using the squeeze flow approach (Wang et al., 1998; Muthukumarappan et al., 1999).

Stretch is the ability of the CN network to maintain its integrity (not break) when a continuous stress is applied to the cheese. For a cheese to stretch, CN molecules must interact with each other and release stress (due to stress applied to the cheese) and become pliable (but still maintain sufficient contact between them or the fibers break). Time is again important as cheese may crack or fibers break if the cheese is rapidly stretched, whereas if it is performed slowly stretch properties (quality) may be attained. A variety of methods have also been developed to try to quantify the stretchability of cheese (Cavella et al., 1992; Apostolopoulos, 1994; Ak and Gunasekaran, 1995; Guinee and O'Callaghan, 1997). From the viewpoint of the con- sumer eating pizza, stretch probably means the ability of cheese to form fibers of reasonable tension when a slice is lifted up from the rest of the pizza. Mature cheese can sometimes form few long (fine) fibers or strings, whereas very young cheese can be too tough and fibrous. Presumably, a method to quantify stretch quality should take these two contrasting and probably undesirable stretch characteristics into account when developing a stretch test, e.g., in a tension-type test high force or stress values may indicate toughness, whereas if only the length of stretch is determined, then it is possible that single long strings could be determined that relate to a stringy cheese. Obviously, it is difficult to have a single technique to objectively assess the "quality" of stretch.

The technique or approach used to assess the melt, stretch, or flow properties of cheeses has a large impact on the observed behavior. This is already observed in the industry, where is it well known that the type of oven, i.e., impinger (forced-air) or conventional, markedly influences cheese performance on pizza. Test conditions such as rate of heating (which is influenced by the size and geometry of the cheese, composition of cheese, type of heating system), and timescale of application of stress (applied frequency in an oscillatory rheology test or loading time with a squeeze-flow technique) greatly influence the results obtained. In some tests, cheeses are subjected to a very high rate of heating (e.g., $10^{\circ} \mathrm{C} / \mathrm{min}$ ), but it is often not clear if the cheeses actually attained this temperature, as this would depend on the size of the cheese sample, its moisture content, heat capacity and having rapid heat transfer. When cheese is heated, the viscoelastic nature of cheese results in cheese behaving at short timescales (high frequency) like an elastic material with a high elastic modulus and a low loss tangent, as there is insufficient time for relaxation of bonds. Over longer timescales (low frequency) cheese behaves much more viscous-like with a low elastic modulus and high loss tangent as many bonds have had sufficient time to relax.

The medium used to heat the cheese can influence stretchability as cheese cools and dries out rapidly in air (case hardening), whereas if cheese is stretched under hot oil it can be stretched much farther. Many other experimental variables, such as the speed of stretching, amount of cheese, and test temperature all influence the degree of stretchability of cheese, which makes it difficult to compare work done using different techniques.

\section{Molecular Interactions Involved in Melt, Stretch, and Related Characteristics}

Information on the molecular interactions occurring in cheese during heating can be obtained from dynamic 

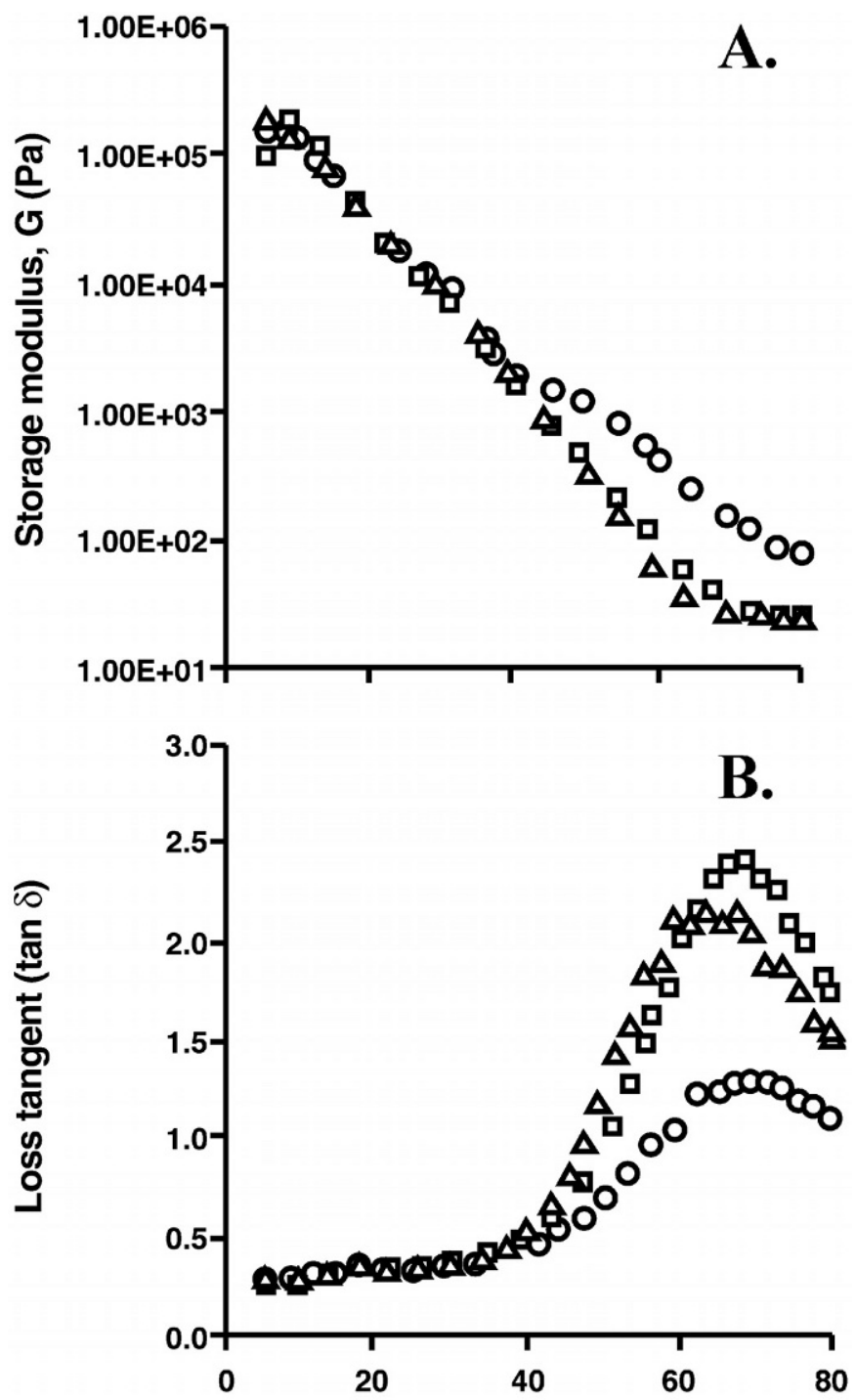

Temperature $\left({ }^{\circ} \mathrm{C}\right)$

Figure 1. Effect of temperature on the storage modulus (a) and loss tangent (b) of Cheddar cheese at $2 \mathrm{~d}(\bigcirc), 14 \mathrm{~d}(\square)$, and $1 \mathrm{mo}(\triangle)$. Cheese was heated at $1^{\circ} \mathrm{C} / \mathrm{min}$ and the frequency and applied strain were $0.1 \mathrm{~Hz}$ and $0.2 \%$, respectively.

oscillatory rheometry. When cheese is heated, there is a dramatic decrease in the total number and/or strength of bonds in the cheese matrix, which is indicated by the steady decrease by several orders of magnitude in the dynamic moduli ( $\mathrm{G}^{\prime}$ and $\left.\mathrm{G}^{\prime \prime}\right)$, and an increase in $\tan \delta$ (at temperatures $\geq 40^{\circ} \mathrm{C}$ ) (Taneya et al., 1979; Horne et al., 1994; Guinee et al., 1999; Figure 1). This change in the dynamic viscoelastic parameters indicates that at elevated temperatures cheese changes to a more viscous-like material compared with unmelted cheese. Part of the initial softening of cheese at $\leq 40^{\circ} \mathrm{C}$ is related to the melting of fat, but the major overall effects relate to $\mathrm{CN}-\mathrm{CN}$ interactions. Cheddar cheese at age $14 \mathrm{~d}$ had the highest value obtained by $\tan \delta$ during the heating profile (Figure 1b) presumably reflecting the influence of solubilization of some of the residual CCP as well as initial cleavage of $\alpha_{\mathrm{s} 1}-\mathrm{CN}$ (the impact of ripening is discussed in detail in a later section). Differential scanning calorimetry of cheese reveals several peaks in the temperature range 10 to $40^{\circ} \mathrm{C}$ reflecting the melting of fat but no major features are observed when the cheese is heated from 40 to $70^{\circ} \mathrm{C}$ (Park et al., 1984). This suggests that melting of cheese is primarily determined by the number and strength of the CN-CN interactions (Park et al., 1984). A schematic diagram of the matrix in unmelted and melted cheese is shown in Figure 2.

Hydrophobic interactions play a major role in determining the conformation and interaction of protein molecules (Bryant and McClements, 1998). They manifest themselves as strong attractive forces between nonpolar groups separated by water. However, they originate due to the ability of water molecules to form relatively strong hydrogen bonds with other water molecules. Hydrophobic interactions tend to increase in strength with temperature (Bryant and McClements, 1998), which may reduce the size of the contact area between $\mathrm{CN}$ particles (as these individual molecules contract on themselves), and the net result is a reduction in overall gel strength (Zoon et al., 1988b). Various types of electrostatic interactions are also likely to be important in cheese and are manifested as charge repulsion between similar charges on proteins, plus minus ( \pm ) charge interactions, salt bridges, and CCP bridges (Walstra and van Vliet, 1986). Electrostatic repulsion increases with increasing temperature (Bryant and McClements, 1998). The solubility of $\mathrm{Ca}$ and the CCP equilibrium are also dependent on temperature (Horne, 1998). We can apply the Horne model to the situation in which cheese is heated. This approach suggests that the strength of $\mathrm{CN}-\mathrm{CN}$ bonds in a matrix is the result of a localized balance of hydrophobic interactions (attractive) and electrostatic repulsion. In Figure 3 a summary of the proposed interactions occurring in the cheese matrix are outlined. Although hydrophobic interactions increase with increasing temperature, the net result may be a weakening of the gel due to reduction in contact area between CN molecules. Hydrogen bonding (attractive) also decreases with increasing temperature. Electrostatic repulsion increases with increasing temperature (Bryant and McClements, 1998). This suggests that the balance would be shifted towards more repulsion and a weakening of the matrix, which is what is observed. It should be noted that hydrophobic interactions increase up to a maximum at about 60 to $70^{\circ} \mathrm{C}$, at which point they begin to slowly lose strength 

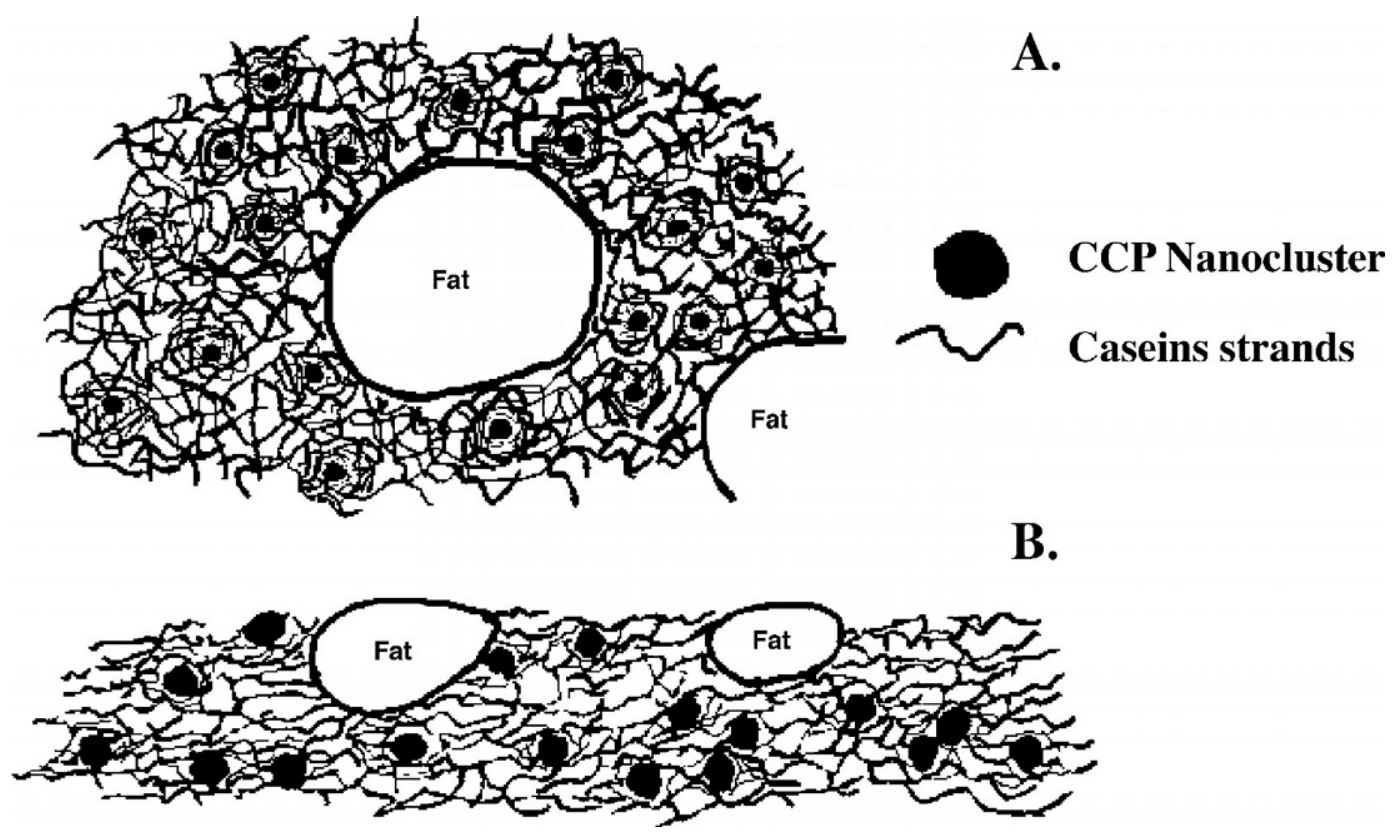

Figure 2. Schematic drawing of the structure of unmelted (A) and melted cheese (B).

as the temperature is further increased (Bryant and McClements, 1998). This suggests that at high temperatures $\left(>60^{\circ} \mathrm{C}\right)$ there may be some further changes in the energy balance that would influence the strength of the cheese matrix.

Although all cheeses soften with increasing temperature (suggesting that general or universal properties of the $\mathrm{CN}$ molecules are responsible, as was suggested in the previous paragraph), some cheeses do not melt very much, e.g., cheese with a very low $\mathrm{pH}$ cheeses, e.g., $<4.9$, as in cottage cheese or cheese made from severely heated milk (e.g., queso blanco). In these cheeses the dynamic moduli decrease, but $\tan \delta$ hardly increases at high temperatures $\left(>40^{\circ} \mathrm{C}\right)$ in contrast to most cheeses. This suggests that when we modify the strength/type of $\mathrm{CN}$ interactions in cheese we can upset the usual balance that facilitates the occurrence of melting, which involves a proportionally larger decrease in $\mathrm{G}^{\prime}$ compared with $\mathrm{G}^{\prime \prime}$ at temperatures $>40^{\circ} \mathrm{C}$. In the case of cheese made from heated milk we have the presence of disulfide bonds in the matrix that are permanent covalent bonds between $\kappa$-CN and $\beta$-lactoglobulin. When this cheese is heated, there is the usual increase in hydrophobic attractive forces, but presumably the ability for $\mathrm{CN}$ molecules to contract is hindered by the covalent bonds that act to cross-link the matrix. The presence of disulfide bonds also increases the elastic character of the gel similar to the situation in heatinduced whey protein gels (which coincidentally do not melt at high temperatures, i.e., they form irreversible gels). In cheeses with a very low $\mathrm{pH}$ value, electrostatic repulsion between $\mathrm{CN}$ molecules is greatly reduced due to the proximity of the system to the isoelectric point of $\mathrm{CN}$, which strengthens the bonding between $\mathrm{CN}$ molecules and adversely affects melting ability. A much greater understanding is needed of the detailed mecha$\operatorname{nism}(\mathrm{s})$ and specific types of bonds that are involved in facilitating melt.

With increasing temperatures there is greater thermal motion of molecules, particles, and strands. At high temperature there is more rapid relaxation of proteinprotein bonds and a change to a more liquid-like character as indicated by the increase in $\tan \delta$. The decrease in the dynamic moduli and increase in $\tan \delta$ indicate an increased likelihood of bonds relaxing or breaking, which facilitates flow of the cheese mass. For melting or flow to occur in a curd piece, several of the rheological parameters should be favorable. Reversibility in the bonding between $\mathrm{CN}$ molecules should be loose enough to relax and allow movement over other $\mathrm{CN}$ molecules. New bonds may form with these new neighbors, but these bonds must also be of a short lifetime to allow further relaxation and movement.

When cheese is stretched at high temperature, several additional aspects must be included (but the cheese must melt, soften, and flow to allow it to be stretched or the fibers will break). If the internal stresses resulting from the application of the force during stretching are not released easily and are held within the cheese, fibers may break ("feathering"), whereas if the 
Casein interactions in the cheese matrix follow the two bonding pathways of the dual-binding model of the casein micelle, i.e. through $+/$ - bridges between phosphoseryl clusters and positively charged calcium phosphate nanoclusters and through hydrophobic interactions between hydrophobic regions on opposing molecules. If the interactions in the cheese matrix through the hydrophobic pathway can be treated as in a hydrophobic colloid:

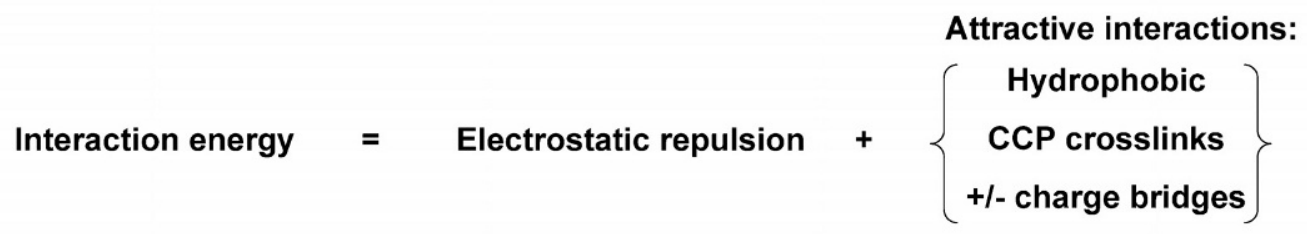

The strength of hydrophobic attractions is compensated by electrostatic repulsion, e.g., the neutralizing effect of the presence of CCP nanoclusters assists in strengthening the hydrophobic interactions. Conversely, the loss of the nanoclusters when CCP is solubilized leaves a multiply negatively charged site which considerably weakens hydrophobic interactions along this pathway.

During heating hydrophobic interactions tend to increase in strength with temperature which may reduce the size of the contact area between $\mathrm{CN}$ particles (as these individual molecules contract on themselves) and the net result is a reduction in the moduli of the matrix. Electrostatic repulsion increases with increasing temperature. Our assumption is that for melt to occur, when a cheese is heated, electrostatic repulsion $\geq$ attractive interactions.

B.

\begin{tabular}{|c|c|c|c|}
\hline $\begin{array}{c}\text { Cheesemaking } \\
\text { conditions/situation }\end{array}$ & Electrostatic repulsion & Attractive interactions & $\begin{array}{c}\text { Net impact } \\
\text { on melt }\end{array}$ \\
\hline $\begin{array}{l}\text { Acid production }(\mathrm{pH} \\
\geq 4.9)\end{array}$ & $\begin{array}{l}\text { Loss of CCP increases localized } \\
\text { repulsion by exposing } \\
\text { phosphoserine residues }\end{array}$ & $\begin{array}{l}\text { Decreases due to fewer } \\
\text { CCP crosslinks }\end{array}$ & Increases \\
\hline $\begin{array}{l}\text { Very low pH values } \\
(<4.9)\end{array}$ & $\begin{array}{l}\text { Repulsion decreases as caseins } \\
\text { approach their isoelectric point }\end{array}$ & $\begin{array}{l}\text { Hydrophobic interactions } \\
\text { increase with } \\
\text { concomitant reduction in } \\
\text { electrostatic repulsion, } \\
\text { more }+/ \text { - charge bridges }\end{array}$ & Decreases \\
\hline Proteolysis & $\begin{array}{l}\text { Decreases when charged peptides } \\
\text { are hydrolyzed }\end{array}$ & $\begin{array}{l}\text { Decreases as total } \\
\text { number of protein- } \\
\text { protein bonds is reduced }\end{array}$ & Increases \\
\hline $\begin{array}{l}\text { CCP solubilization } \\
\text { post-manufacture }\end{array}$ & $\begin{array}{l}\text { Further loss of CCP increases } \\
\text { localized repulsion by exposing } \\
\text { phosphoserine residues }\end{array}$ & $\begin{array}{l}\text { Decreases due to less } \\
\text { CCP crosslinks }\end{array}$ & Increases \\
\hline $\begin{array}{l}\text { Concentrated milk } \\
\text { (without corrective } \\
\text { measures) }\end{array}$ & $\begin{array}{l}\text { Decreases due to higher CCP } \\
\text { content (per g of casein) }\end{array}$ & $\begin{array}{l}\text { Increases due to more } \\
\text { CCP crosslinks (per g of } \\
\text { casein) }\end{array}$ & Decreases \\
\hline $\begin{array}{l}\text { Use of emulsifying } \\
\text { salts in processed } \\
\text { cheese }\end{array}$ & $\begin{array}{l}\text { Increases due to exposure of } \\
\text { phosphoserine residues when CCP is } \\
\text { partly chelated, these salts can } \\
\text { increase } \mathrm{pH} \text { and thereby repulsion }\end{array}$ & $\begin{array}{l}\text { Decreases due to less } \\
\text { CCP crosslinks }\end{array}$ & Increases \\
\hline
\end{tabular}

Figure 3. Summary of casein interactions involved in melting (A) and examples of how various cheese manufacturing conditions affect casein interactions and impact meltability (B). 
cheese dissipates most of the energy applied to it, it will also not stretch but will act like a viscous liquid. This kind of cheese characteristic is often called "soupy". (Coincidently a soupy cheese is less likely to exhibit blistering because gas is easily released during baking without forming a permanent "bubble" that in firmer, e.g., young low fat cheese results in blistering and browning). Thus, there is a critical level of energy storage and dissipation that allows a CN network to melt and stretch. At a molecular level this has been described in terms of the relaxation of bonds between molecules (and indicated by the loss tangent parameter). In general, energy dissipation may be caused by various mechanisms, e.g., melt or flow of the material itself (lasting deformation). For a cheese to stretch, there needs to be a cohesive, continuous network of CN. If the CN aggregates are not linked, there can be no stretch. One way of looking at the stretching process is to view $\mathrm{CN}$ molecules in cheese as entangled polymers (i.e., fibers) that are sticky at high temperatures. If the CN network is extensively hydrolyzed as a result of proteolysis, there is a substantial decrease in stretch, as this disrupts the continuity of stress-carrying fibers and strands. If the protein-proteins interactions are too strong (i.e., the use of too low a stretching temperature or too much $\mathrm{Ca}$ associated with the $\mathrm{CN}$ molecules) then stretching is impaired, and it is more likely to break the curd rather than having it stretch or flow. The stretching characteristics of cheese are related to the relatively high concentrations of intact $\mathrm{CN}$ and to a critical level of $\mathrm{Ca}$ and $\mathrm{P}$ (Lucey and Fox, 1993). The stretch characteristic requires that the $\mathrm{CN}$ molecules interact closely, but at the same time the bonds holding the $\mathrm{CN}$ molecules together must relax (break) and reform very quickly. These criteria are met within a narrow $\mathrm{pH}$ range or in a cheese with sufficient loss of $\mathrm{Ca}$ (Lucey and Fox, 1993).

Several studies have correlated rheological parameters, such as the initial $\mathrm{G}^{\prime}$ of the unmelted cheese and the maximum value for tan $\delta$ during heating, with (empirical) functional properties such as meltability and flowability of cheese (Ustanol et al., 1994; Guinee et al., 1999; Mounsey and O'Riordan, 1999). As cheese ages, meltability increases, but stretch properties decrease (as only weak fibers are formed) due to excessive proteolysis. During Mozzarella cheese manufacture, the hot curd exhibits considerable stretch. Optimum (as determined by the consumer or end user) functionality depends on cheese attaining the desired melt, stretch, flow, degree of free oil, type and extent of blisters, and color characteristics. Several important factors that influence the textural and rheological properties of cheese, such as Ca content, milk heat treatment, addition of salt and aging, are discussed in the next section.
Knowledge about relaxation mechanisms and times, and their relationship with both frequency and temperature is limited (Taneya et al., 1979; Subramanian and Gunasekaran, 1997). The concept of glass transition as applied to melting of cheese needs to be investigated as it may assist in probing this complex phenomenon. The relevant rheological data needs to span as wide a range of frequency, stress, and temperature as possible. Even if the concept of glass transition is unsuccessful (which is a likely outcome), the mapping of the stressfrequency-temperature space will allow reconciliation of the disparate behavior reported in the literature because the conditions employed there often sampled only one particular region of the stress-frequency-temperature space.

\section{HOW PROCESSING CONDITIONS USED IN CHEESE MAKING INFLUENCE THE MOLECULAR INTERACTIONS RESPONSIBLE FOR FUNCTIONAL PROPERTIES}

\section{Factors Affecting the Functionality of Cheese}

Many factors influence texture, melt, and stretch properties of cheese. These include cheese composition, $\mathrm{pH}$, interactions between $\mathrm{CN}$ and serum proteins, proteolysis, Ca content, ionic strength, salt content, and manufacturing protocol (especially rate and extent of acid development and curd washing) (Kindstedt, 1991, 1993; McMahon et al., 1993; Rowney et al., 1999; Guinee, 2002) (Figure 4). Interactions between CN molecules control the melt or flow properties of cheese. Therefore, the more fat that is in the cheese the less dense the CN network becomes, and the cheese will stretch and melt faster at a lower temperature. The effects of several specific factors on the functionality of melted cheese are discussed in detail. A summary of the possible $\mathrm{CN}$ interactions that are involved in melting as well as examples of how cheese manufacturing conditions influence these interactions is shown in Figure 3.

\section{Composition of Milk and Cheese}

The behavior and properties of the protein matrix dominate the textural and rheological properties of cheese, such as rigidity, elasticity, viscoelasticity, and meltability. Increasing the moisture content or increasing the ratio of moisture to protein (nonfat substances) in cheese weakens the rigidity as the volume fraction of protein decreases (Walstra and van Vliet, 1982), and this influences a wide range of textural characteristics (e.g., softness, shreddability, and meltability). Fat can be considered as inert filler between aggregates of $\mathrm{CN}$ micelles, unless milk is homogenized (van Vliet, 1988). Ruegg et al. (1991) showed that fat and moisture con- 


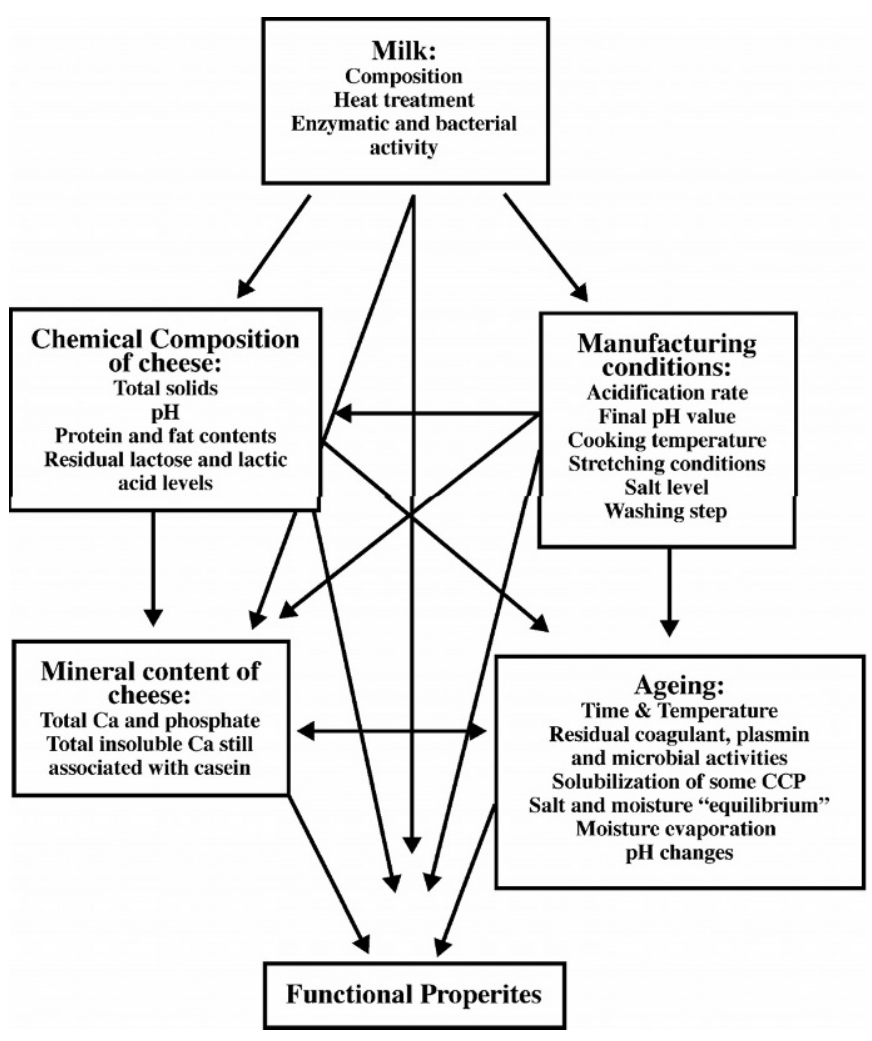

Figure 4. Interrelationships between factors affecting the functional properties of cheese.

tent of cheese play an important role in the melting of cheese. However, they also reported that fat content is not always directly related to meltability, as its effect may be confounded by the ratio of other components like protein and moisture (Walstra and van Vliet, 1982). Chen et al. (1979) concluded that fat had little influence on the hardness of a wide variety of natural and processed cheeses. Olson and Bogenrief (1995) observed a biphasic relationship between FDM (fat-in-the-DM) and thermal meltability. Changes in FDM from 18 to $45 \%$ FDM had little effect on meltability, but a dramatic increase occurred when FDM levels increased above $45 \%$. Because temperature directly influences the ratio of solid to liquid fat, textural properties need to be performed under well-defined temperature conditions.

\section{pH and Mineral Content of Cheese}

Cheese $\mathrm{pH}$ and mineral content have a major influence on the structure and texture of cheese (Lawrence et al., 1987; Lucey and Fox, 1993). pH and mineral content are related as the rate of acid production (e.g., $\mathrm{pH}$ values at renneting and draining) determines the mineral content of cheese. Different manufacturing conditions used in the production of different cheese varieties result in characteristic compositions and a typical concentration of Ca and P (Lucey and Fox, 1993). According to Lucey and Fox (1993), the proportion of undissolved $\mathrm{Ca}$ associated with $\mathrm{CN}$ particles in cheese was a much more important structural parameter than the total Ca content. Lucey and Fox (1993) also proposed that instead of the total Ca content, it is more useful to use the ratio of $\mathrm{Ca}$ to protein as a structural parameter. During aging of cheese, the proportions of $\mathrm{Ca}$ associated with $\mathrm{CN}$ and soluble $\mathrm{Ca}$ continue to change slowly. In Cheddar cheese the proportion of $\mathrm{Ca}$ that is associated with $\mathrm{CN}$ decreased from $\sim 64$ to $~ 56 \%$ of total cheese Ca during the first 4 wk (Hassan and Lucey, 2001). Applying the Horne model to understand the effects of acid development, we can view a reduction in $\mathrm{pH}$ as decreasing the amount of CCP crosslinking and increasing electrostatic repulsion between the newly exposed phosphoserine groups of $\mathrm{CN}$ molecules. The net result of this shift in the Ca equilibrium should be a weakening of cheese structure and an increase in meltability (if all other factors are unchanged). If the casein system did not contain CCP, then acid development would simply decrease electrostatic repulsion and strengthen the association between $\mathrm{CN}$ molecules (as occurs in acid coagulation of milk or in very low $\mathrm{pH}$ cheeses).

In a recent study of Emmental cheese, 17 of the 91 peptides identified at the end of the ripening period were phosphopeptides derived from $\alpha_{\mathrm{s}^{2}}$ and $\beta$-CN (Gagnaire et al., 2001b). It is possible that solubilization of CCP exposes phosphoserine residues and makes them more susceptible to hydrolysis (Fox, 1970). Cleavage of phosphopeptides would also reduce electrostatic repulsion between CN molecules in the cheese matrix. Much more research is needed to understand the relationship between functional properties and the amount of insoluble Ca present in cheese as a function of ripening time and in cheese made by various methods.

It has been suggested that the texture of Cheddar and Mozzarella cheese may be more dependent on $\mathrm{pH}$ than on any other factor (Lawrence and Gilles, 1982), although it is more likely that the proportion of $\mathrm{Ca}$ phosphate in an undissolved form varied in these types of cheeses, depending on the $\mathrm{pH}$ value, and this may have contributed to the reported differences in texture (Lucey and Fox, 1993). Again, using the Horne model, we can suggest that even if the total Ca content of two (hypothetical) cheeses were similar, the cheese with the lower proportion of undissolved CCP should exhibit more of the characteristics of a lower $\mathrm{pH}$ cheese (i.e., more meltable, more brittle).

Another complication is $\mathrm{pH}$ history (i.e., changes in cheese $\mathrm{pH}$ with time), as in some cheeses the $\mathrm{pH}$ can increase by 0.1 to $0.2 \mathrm{pH}$ units in the first couple of 
days, but the effects of the original low pH could still have an important effect on functional properties (e.g., it could cause some additional demineralization, more than might have been expected for the "final" high $\mathrm{pH}$ value). The $\mathrm{pH}$ of many cheeses, such as Mozzarella, often slightly increases during ripening. This is especially true in cheeses in which there is little fermentation of residual lactose postmanufacture due to a high salt-in-moisture content and/or a salt sensitive starter culture (or where the residual lactose content is greatly reduced by washing). The slight $\mathrm{pH}$ increase is due to slow solubilization of CCP because this process causes a slow increase in $\mathrm{pH}$ when milk is being acidified (Singh et al., 1997). In cheeses in which residual lactose is fermented, the production of lactic acid can offset the usual tendency for a $\mathrm{pH}$ increase, with the result that the cheese $\mathrm{pH}$ may remain relatively stable.

It has long been known that there is greater curd demineralization when more of the acid is developed in the vat (i.e., by preacidification of milk, draining at a low $\mathrm{pH}$ value) (Lucey and Fox, 1993). It is also well recognized in cheeses with the same $\mathrm{pH}$ value, that a cheese made using direct acidification (i.e., lower coagulation $\mathrm{pH}$ ) rather than starter cultures will have greater curd demineralization (Keller et al., 1974). This also implies that at a given $\mathrm{pH}$ the cheese with the least amount of bound Ca will melt and flow faster and will do so at lower heating temperatures. With direct acid addition (also depends on the type of acid) curd will stretch, melt, and flow at a higher $\mathrm{pH}$ value than in cheese made with starter culture, e.g., Mozzarella cheese made by direct acidification with lactic acid has acceptable stretching properties at $\mathrm{pH} 5.6$ (Keller et al., 1974; Metzger et al., 2001). It is not clear whether the faster rate of solubilization of CCP in milk (or the initial curd particles) rather than in curd reflects some sort of physical inhibition ("shielding") of the removal of $\mathrm{Ca}$ from curd particles by the formation of an outside membrane (Guinee et al., 2002) or if the CCP solubility is decreased when the moisture content of the medium (i.e., curd or cheese) decreases. We believe that the latter explanation may be the most likely cause, but this area needs to be investigated.

Arnott et al. (1957) and Harvey et al. (1982) reported that the $\mathrm{pH}$ of mature cheese sometimes showed a significant correlation with melt. Olson et al. (1996) reported that $\mathrm{pH}$ was not the single major factor in determining the meltability of Cheddar cheese. Initiating whey drainage at $\mathrm{pH} 6.4$ compared with 6.15 resulted in significantly higher Ca levels in Mozzarella cheese (Yun et al., 1995). During acidification, the loss of Ca from the CN particles results in a weaker association (increased electrostatic repulsion and loss of CCP nanoclusters) between $\mathrm{CN}$ molecules, which increases the melt and flow of the cheese when heated. The $\tan \delta$ of acid-induced gels made from heated milk (Lucey, 2002) and milk gels made by a combination of rennet and acidification (Roefs et al., 1990; Lucey et al., 2000) exhibit a maximum at $\mathrm{pH} \sim 5.2$, probably due to the loss of CCP from the casein matrix while $\tan \delta$ decreases at low $\mathrm{pH}$ values. If the $\mathrm{pH}$ becomes too low (e.g., $\mathrm{pH}<$ 4.9), there is a reduction in melt, stretch, and curd cohesion (Lawrence et al., 1987). At $\mathrm{pH}$ values $\leq 4.9$, CN assumes an increasingly more compact conformation (body may become grainy), and the texture of the (unmelted) cheese becomes shorter, and there is an increase in brittleness and fracturability (Luyten et al., 1991; Olson et al., 1996). Strain at fracture is closely related to the $\mathrm{pH}$ of cheese (Luyten et al., 1987; Luyten et al., 1991; Olson and Bogenrief, 1995). Applying the Horne model to the situation in which we have very low $\mathrm{pH}$ values (i.e., $\leq 4.9$ ), there should be stronger hydrophobic association between individual CN molecules with less electrostatic repulsion as the CN approach their isoelectric point. There is also a substantial reduction in the concentration of $\mathrm{Ca}$ and the proportion of undissolved CCP may also be lower; both of these would reduce the amount of CCP crosslinking material. The net impact of a very low $\mathrm{pH}$ is the dominant influence of increased association between $\mathrm{CN}$ molecules, which reduces melt and the low levels of $\mathrm{Ca}$ and $\mathrm{CCP}$ decreases stretch and increases brittleness.

Some melting and stretching of cheese occurs at higher $\mathrm{pH}$ values (e.g., even at $\mathrm{pH} 6.0$ in directly acidified cheese made with lactic acid), although much higher curd temperature is needed to get the cheese to melt at all and the cheese remains tough and breaks easily. Another example that indicates that the Ca content, and not $\mathrm{pH}$, is more important in controlling meltability is the use of Ca chelating acids (such as citric) in the manufacture of directly acidified Mozzarella. For a similar $\mathrm{pH}$ value, the cheese acidified with a Ca chelating acid is much softer and exhibits greater meltability than cheese made with a nonchelating acid (e.g., $\mathrm{HCl}$ or lactic acid) (Keller et al., 1974). If too much Ca is removed by the use of a Ca chelating agent to acidify milk to a low pH value (e.g., 5.4) then the cheese can become very tacky as it loses cohesiveness and becomes very viscous (Keller et al., 1974). When the total Ca concentration in cheese is lowered by processing steps such as preacidification of milk or use of Ca chelating acids, presumably the amount of $\mathrm{Ca}$ associated with $\mathrm{CN}$ is also lowered. A reduction in the amount of $\mathrm{Ca}$ associated with $\mathrm{CN}$ molecules (insoluble $\mathrm{Ca}$ ) increases charge repulsion between $\mathrm{CN}$, and this makes the matrix weaker and more meltable, provided the $\mathrm{pH}$ of cheese does not drop too far (e.g., remains $\geq 4.9$ ). The precise amount of demineralization required to make 
cheese melt and flow without exceeding an optimum level at which the cheese becomes too fluid has not been defined scientifically, but, in practice, cheesemakers use demineralization (through $\mathrm{pH}$ control) of $\mathrm{CN}$ to control physical properties such as melt and stretch.

Washing the curd or diluting the whey during cooking (especially with a little salt in the water) will result in an increase in the loss of some of the Ca associated with $\mathrm{CN}$ particles and more effective removal of the soluble components (e.g., soluble Ca). Calcium binding may also be reduced by the decrease in ionic strength. A small amount of salt in the wash water may aid in the solubilization of $\mathrm{Ca}$, which increases the electrostatic repulsion between $\mathrm{CN}$ molecules, and the cheese will stretch, melt, and flow faster and at a lower temperature. However, an increase in the hydrogen ion concentration (development of acidity) is much more effective than salt in displacing $\mathrm{Ca}$.

In model cheese curds that were made with $\mathrm{pH}$ values between 5.45 to 6.05 (Ramkumar et al., 1998) or where the $\mathrm{pH}$ of Mozzarella was increased by exposure to an ammonia atmosphere (Kindstedt et al., 2001), there was an increase in the elastic modulus and apparent viscosity with increasing $\mathrm{pH}$. Presumably, in cheese made with a higher $\mathrm{pH}$ value there was more residual Ca phosphate associated with $\mathrm{CN}$. In cheese in which the original $\mathrm{pH}$ was increased postmanufacture, a combination of factors were probably involved in the increase in the apparent viscosity such as precipitation of Ca phosphate as the $\mathrm{pH}$ approached 6.0 (Lucey and Fox, 1993) and screening of negative charges by Ca ions which would lessen electrostatic repulsion. Lucey et al. (1997) showed that CCP-depleted CN particles, formed at $\mathrm{pH} \sim 5.3$, disintegrated due to increased electrostatic repulsion as the $\mathrm{pH}$ was restored to normal values when these CN were dialyzed against water or simulated milk ultrafiltrate that had no Ca or phosphate present. When the concentration of $\mathrm{Ca}$ in the simulated milk ultrafiltrate was increased, there was considerably less dissociation of $\mathrm{CN}$ when the $\mathrm{pH}$ was increased, as presumably the added $\mathrm{Ca}$ helped to reduce electrostatic repulsion by increasing the specific binding of $\mathrm{Ca}$ or by screening charged groups (Lucey et al., 1997).

In mold-ripened cheeses (e.g., Camembert, brie, and blue) several parameters lead to the softening of cheese during ripening, including extensive proteolysis of both $\alpha_{\mathrm{s}}$ and $\beta$-CN, $\mathrm{pH}$ increase due to the utilization of lactate and the production of ammonia, precipitation of $\mathrm{Ca}$ phosphate on the exterior rind, and the migration of $\mathrm{Ca}$ and phosphate from the interior (due to $\mathrm{pH}$ gradient), high levels of demineralization due to low $\mathrm{pH}$ (4.5 to 4.6) of the curd, as well as the high moisture content of these soft cheeses (Gripon, 1993). The $\mathrm{pH}$ increase during ripening increases electrostatic repulsion be- tween CN molecules, especially as there is concomitant migration of $\mathrm{Ca}$ phosphate from the interior to the rind, which exposes more phosphoserine residues.

Residual CCP in cheese is also a powerful $\mathrm{pH}$ buffer, and in combination with buffering by lactic acid $\left(\mathrm{pK}_{\mathrm{a}}\right.$ 3.95) produced by the starter culture, helps to keep the $\mathrm{pH}$ of most cheese varieties $\geq 5.0$ (Lucey and Fox, 1993), unless there is a high level of demineralization (e.g., preacidification of milk) or a high content of residual lactose in cheese, which, if fermented, greatly increases the lactic acid content.

\section{Ripening}

During maturation, several biochemical events (primarily proteolysis, glycolysis, and lipolysis) as well as slow solubilization of some of the residual CCP change curd from a rubbery, bland product to mature cheese with a characteristic flavor, texture, and aroma. During aging, the most important biochemical reaction in most varieties is proteolysis (Fox et al., 1990). The microstructure of Cheddar (and presumably other varieties) probably consists of an extensive network that includes both $\alpha_{\mathrm{s} 1}$-CN and $\beta$-CN (which are the two main types of $\mathrm{CN}$ in cheese) as well as the other $\mathrm{CN}$.

The cheese matrix is made of interconnected $\mathrm{CN}$ particles, and the solubilization of CCP and hydrolysis of these molecules will increase softening and melt but decrease stretch. In cheese, the early cleavage of $\alpha_{\mathrm{s} 1^{-}}$ $\mathrm{CN}$ at $\mathrm{Phe}_{23}-\mathrm{Phe}_{24}$ by residual chymosin activity has been associated with a decrease in firmness (De Jong, 1976; Creamer and Olson, 1982; Creamer et al., 1982). The $\beta$-CN undergoes little proteolysis by chymosin in cheese and, when hydrolysis does occur it has been associated with the accumulation of bitter peptides (Fox et al., 2000). Hydrolysis of $\beta$-CN by the microbial coagulant Cryphonectria parasitica increases melt (Bogenreif and Olson, 1995). Hydrolysis of $\alpha_{\mathrm{s} 1}-\mathrm{CN}$ was similar in cheeses made with $C$. parasitica and calf rennet, but hydrolysis of $\beta$-CN was significantly greater in cheeses made with $C$. parasitica. The type of milk-clotting enzyme did not significantly affect texture profile analysis (TPA) hardness of Mozzarella cheese during maturation, but meltability of cheeses made with C. parasitica proteinase was significantly higher than that of cheeses made with calf rennet (Yun et al., 1993). In practice, it is likely that the hydrolysis of both $\alpha_{\mathrm{s} 1}$-and $\beta$-CN during storage can increase the meltability of all cheeses by weakening the number (and strength) of the proteinprotein interactions between $\mathrm{CN}$ molecules.

Plasmin is the principal indigenous proteinase in milk (Grufferty and Fox, 1988) and elevated activity in milk results in a reduction in gel strength (Srinivasan and Lucey, 2002). Plasmin is active on all CN (although 
it has very little activity on $\kappa$-CN), but especially $\alpha_{\mathrm{s} 2^{-}}$ and $\beta$-CN. Plasmin may become slightly more important as a ripening agent in high cooked cheeses (e.g., Emmental and Mozzarella) because its activity may be increased by heating (which destroys an inhibitor of an activator of plasminogen) (Farkye and Fox, 1990). Extensive proteolysis of $\mathrm{CN}$ in a high moisture cheese (or coupled with a high fat content) leads to a cheese that is softer and will flow at a much lower temperature (even as low as room temperature). Most varieties of cheese with a $\mathrm{pH}$ of about 5.2 will stretch in a manner similar to that of Mozzarella, but stretchability is rapidly lost (but not meltability, which continues to increase with age) by breakdown of the CN network by residual coagulant (Lucey and Fox, 1993). In pastafilata cheeses, the high temperature applied to curd in the cooker/stretcher greatly reduces residual coagulant activity (although this depends on the heat treatment given to the curd), and plasmin activity may become more important than in cheeses in which the curd does not have a high temperature processing step. Guinee et al. (2002) reported that the stretchability (defined as the length of longest fibers; Guinee and O'Callaghan, 1997) of Mozzarella increased rapidly in the first $10 \mathrm{~d}$ and then continued to slowly increase for up to $70 \mathrm{~d}$ of ripening. Other studies (Kindstedt et al., 1989; Oberg et al., 1991) using apparent viscosity of the melted cheese (measured by helical viscometry) as an indicator of stretchability reported that stretch decreased during ripening. In practice (e.g., as assessed by fork), the stretch properties (i.e., quality) of cheese tend to decrease with age due to proteolysis (unless curd was given a very high heating in the cooker/stretcher and/ or cheese was stored at very low temperatures). These contrasting results again illustrate the difficulties in interpreting work done with different techniques from different types of cheeses.

The fracture strain of semi-hard and hard cheese decreases during ripening, although the trends for fracture stress are more variable (Prentice et al., 1993; Luyten and van Vliet, 1996). The increase in the fracture stress of mature Gouda cheese was ascribed to moisture loss during ripening (Visser, 1991; Luyten and van Vliet, 1996). Lane et al. (1997) reported that among the textural properties of Cheddar cheese, TPA cohesiveness was most related to primary proteolysis with a trend of decreasing with increasing proteolysis. Rohm et al. (1992) using multiple regression analysis of 48 Swiss-type cheeses reported only weak correlations $(r<$ 0.45 ) between various rheological parameters (fracture stress, fracture strain, and modulus of deformability) with several different indices of proteolysis.

Although many studies have investigated the relationship between proteolysis and textural and rheologi- cal changes (e.g., Creamer and Olson, 1982) many different indices of proteolysis (e.g., water soluble $\mathrm{N}, \mathrm{pH}$ 4.6 soluble $\mathrm{N}$, tungstophosphoric acid) have been used, and it does not seem to be clear which index should be the most appropriate. One way of looking at this problem is to assume that once a peptide is cleaved and becomes part of the serum phase, it no longer contributes to the structure and texture of cheese. Thus, the water soluble $\mathrm{N}$ or the $\mathrm{N}$ content of cheese juice might seem like good candidates for relating the extent and type of proteolysis to textural properties. Large peptides that are present in the serum phase continue to be degraded, but it should be remembered that even before they are further broken down they are not contributing to the cheese structure. It is possible that hydrolysis of some peptide bonds does not result in that fragment automatically becoming part of the serum phase as the peptide may remain attached to the matrix due to hydrophobic and electrostatic interactions. Although there is considerable information on proteolysis in most major cheese varieties, there is still limited knowledge on the mechanisms by which enzymatic hydrolysis of $\mathrm{CN}$ influence texture and functional properties (Gagnaire et al., 2001a). Elucidation of these mechanisms may allow the development of specific strategies to produce specific hydrolysis of $\mathrm{CN}$ in order to independently control characteristics such as melt and firmness.

Aging can be thought of as two stages. First, the chemical stage, which includes slow solubilization of CCP (Hassan and Lucey, 2001) and the concomitant rearrangement of $\mathrm{CN}$ particles (Tunick et al., 1997) and secondly the events dealing with proteolysis. The first step may take a few days to several weeks and is an important factor in the increase in meltability of young cheeses. During aging of Mozzarella cheese, changes in electron densities were reported from electron micrographs (Tunick et al., 1997). These changes in electron densities were interpreted as rearrangements of $\mathrm{CN}$. In young cheese the average spacing for these dense regions was $\sim 17 \mathrm{~nm}$, which is approximately the calculated correlation length (spacing) between CCP nanoclusters in CN micelles, which coincidentally are highly electron dense (Holt and Roginski, 2001). As cheese ages, the spacing between these dense regions increases to around $40 \mathrm{~nm}$ by $6 \mathrm{wk}$ (Tunick et al., 1997). It is possible that the solubilization of some of the CCP in cheese would increase the spacing between the remaining nanoclusters. It is also possible that there is growth of some of the larger CCP nanoclusters at the expense of the smaller ones (i.e., a kind of Ostwald ripening). Applying the Horne model to this situation, we can suggest that a reduction in the concentration or number of CCP nanoclusters would reduce CCP 
crosslinking, increase electrostatic repulsion and make it easier for increased relaxation of $\mathrm{CN}-\mathrm{CN}$ bonds.

Direct acid cheeses are suitable for use as a functional ingredient almost immediately after manufacture, and they need little if any proteolysis to attain the desired characteristics, which are primarily determined by the coagulation $\mathrm{pH}$ (and type of acid). In most cheese varieties, proteolytic effects may take several weeks to occur. Little detailed information is available on changes in the chemical and salt equilibria during the initial stages of cheese ripening, and this aspect needs further research.

A variety of other changes can occur during aging. These include rearrangements to the $\mathrm{CN}$ matrix brought about by low storage temperature, moisture loss in cheeses that are not packaged in plastic (e.g., Camembert), $\mathrm{pH}$ changes, which are usually slight but can be significant if the cheese contains considerable quantities of residual lactose that is fermented to lactic acid, and establishment of an approximate salt and moisture equilibrium. In brine-salted cheeses, this is a critical change, often taking several weeks, which has significant effects on proteolysis by chymosin and plasmin, microbial activity, and the ionic strength in which the $\mathrm{CN}$ network resides.

In all cheeses (except some direct acid cheeses) for a day or two postmanufacture some free serum can be observed when the cheese is cut ("watering-off"). In young ( $<10 \mathrm{~d}$ after manufacture) Mozzarella cheese some of the aqueous phase ("expressible serum") can be removed by centrifugation $(12,500 \times g$ for $75 \mathrm{~min})$, but as the cheese ages the amount that can be expressed decreases, and after 2 wk only very little serum is expressed (Guo and Kindstedt, 1995). This centrifugation procedure does not work with lower moisture cheeses, such as Cheddar. If high hydraulic pressure is applied to any cheese (e.g., Cheddar, Emmental) some of the aqueous phase ("juice") can be extracted even in cheese that is aged for several months (Morris et al., 1988; Lucey et al., 1993a). The amount of "juice" that can be obtained also decreased with age for Cheddar (Guinee et al., 2000), Emmental (Thierry et al., 1998) and Camembert (Boutrou et al., 1999). Low moisture part-skim Mozzarella cheese has a higher moisture content $(\sim 46 \%)$ compared with cheeses such as Cheddar ( 36 to $38 \%$ ), and, as a consequence, the rigidity of the matrix is considerably lower. There are many other differences between these two cheeses, e.g., changes induced by the mixer molder process. The water-holding capacity of cheese may depend on the rigidity of the matrix. The reduction in the amount of expressible serum in Mozzarella cheese as it ages is often ascribed to an increase in protein hydration as water is absorbed into the matrix from the original fat-serum channels (or pores) formed during the stretching process (McMahon et al., 1999). Young Camembert, which has a low $\mathrm{pH}$ and low Ca content, readily waters off, but once the $\mathrm{pH}$ increases (due to the activity of the mold) no wateringoff is observed.

A number of considerations seem to be relevant in this matter. The proteins in cheese are highly hydrated as cheese has a water activity $>0.9$ and even buried water molecules in globular proteins can exchange with bulk solvent on a nanosecond to microsecond timescale (Denisov et al., 1997). Similar timescales for the exchange of water molecules have been reported for cheese (Chaland et al., 2000; Kuo et al., 2001), which suggests that a slow water exchange (i.e., a process taking several weeks) is not a likely rate-limiting step causing the reduction in expressible serum in Mozzarella cheese. Some of the observed changes in the water relaxation times in young curd (Kuo et al., 2001) could be due to the slow solubilization of CCP in cheese as a close relationship was reported between proton relaxation times and the solubilization of CCP in milk (Mariette et al., 1993). When the CCP in milk is solubilized by acidification, the phosphate ions that are released from the nanocluster are rapidly protonated, which results in an increase in the hydrogen ion buffering in milk (Lucey et al., 1993b), and a similar phenomenon can occur in cheese (Lucey and Fox, 1993; Lucey et al., 1993a). Concomitant to the solubilization of CCP in cheese, serum absorption occurs and the functional properties change. Metzger et al. (2001) reported that no expressible serum was obtained with directly acidified Mozzarella acidified to $\mathrm{pH} 5.8$ with citric acid, in contrast to acidification with a nonchelating acid (acetic). This could reflect much smaller postmanufacture changes in the Ca equilibrium in this type of cheese due to the "efficient" solubilization of CCP when the milk was directly acidified, especially when this was performed with a Ca-chelating acid. Paulson et al. (1998) reported that some expressible serum could be obtained from directly acidified (using acetic acid) nonfat Mozzarella (moisture contents $\geq 60 \%$ ) that was drysalted (the serum levels were much lower than in Mozzarella made with starter cultures) but not when a hot brine stretching was used. The hot brine stretching method eliminated the need for traditional brining of the cheese, and presumably a more rapid salt-moisture equilibrium was obtained (some exchange of $\mathrm{Na}$ for $\mathrm{Ca}$ may also have occurred as the Ca content was lower with this treatment).

It is possible that it is easier to express some water from a brine-salted cheese before an apparent salt and moisture equilibrium is attained. Diffusion of salt into cheese increases the ionic strength and osmotic pressure of the aqueous phase (Geurts et al., 1974), both of 
which could make it more difficult to express the aqueous phase by low pressure. The amount of expressible serum does not change as much with time in unsalted Mozzarella cheese compared with salted cheese (Guo et al., 1997; Paulson et al., 1998). Kuo et al. (2001) reported that the amount of expressible serum was lower in dry-salted Mozzarella-type cheese (using a modified cheese making procedure in which curd was not stretched in hot water) compared with (traditional) brined-salted Mozzarella. Although the moisture contents and $\mathrm{pH}$ values of these cheeses were similar, the salt concentration was higher in the dry-salted Mozzarella-type cheese, which could also have reduced the amount of expressible serum that could be obtained. Diffusion of salt into cheese also changes the strength of the interactions between protein molecules by screening of charged groups (which reduces electrostatic repulsion but also lessens the number of plus-minus interactions between protein molecules). The impact of salt diffusion on the properties of the cheese matrix is complex and depends on factors such as salt concentration, $\mathrm{pH}$, moisture content, temperature, and Ca concentration (Monib, 1962). It is possible that salt diffusion could influence the expressability of loosely entrapped moisture. We conclude that the observed changes in the amount of expressible water in Mozzarella cheese are caused by the combined effects of slow solubilization of CCP (which exposes charged groups on CN molecules) and ongoing proteolysis. Proteolysis generates two new ionic groups for every peptide bond that is hydrolyzed, and these ionic groups could influence not only the expressability of water from cheese but also textural attributes such as firmness and fracturability (Creamer and Olson, 1982).

In conclusion, using the new dual-binding model for the structure of $\mathrm{CN}$ micelles as a concept to rationalize the nature and type of $\mathrm{CN}-\mathrm{CN}$ interactions occurring in cheese, was demonstrated to be a useful approach. We believe that this is a promising start, which provides an initial framework to help us understand the complex physical and chemical properties of cheese. We believe that future work needs to focus on understanding the basic mechanism(s) involved in processes such as melt [e.g., which bonds are involved and on which (parts of) CN? what is the reason for melt and flow occurring at a certain temperature for a particular cheese sample? how does proteolysis impact melt and flow?]. We know very little about relaxation spectra in cheese, and there is limited rheological data for cheeses over a wide a range of frequency, stress, and temperature.

\section{ACKNOWLEDGMENTS}

The authors appreciate the funding of Dairy Management, Inc., and the Wisconsin Center for Dairy Re- search. DSH thanks the director and staff of the Wisconsin Center for Dairy Research for their hospitality during the period when writing of this review was initiated.

\section{REFERENCES}

Ak, M. M., and S. Gunasekaran. 1995. Measuring elongational properties of Mozzarella cheese. J. Text. Stud. 26:147-160.

Akkerman, J. C., P. Walstra, and H. J. M. van Dijk. 1989. Holes in Dutch-type cheese. 1. Conditions allowing eye formation. Neth. Milk Dairy J. 43:453-476.

Apostolopoulos, C. 1994. Simple empirical and fundamental methods to determine objectively the stretchability of Mozzarella cheese. J. Dairy Res. 61:405-413.

Arnott, D. R., H. A. Morris, and W. B. Combs. 1957. Effect of certain chemical factors on the melting quality of process cheese. J. Dairy Sci. 40:957-963.

Bodyfelt, F. W., J. Tobias, and G. M. Trout. 1988. The Sensory Evaluation of Dairy Products. Van Nostrand Reinhold, New York.

Bogenrief, D. D., and N. F. Olson. 1995. Hydrolysis of $\beta$-casein increases Cheddar cheese meltability. Milchwissenschaft 50:678682.

Bourne, M. C. 1982. Food Texture and Viscosity; Concept and Measurement. Academic Press, San Diego, CA.

Boutrou, R., F. Gaucheron, M. Piot, F. Michel, J.-L. Maubois, and J. Léonil. 1999. Changes in the composition of juice expressed from Camembert cheese during ripening. Lait 79:503-513.

Bryant, C. M., and D. J. McClements. 1998. Molecular basis of protein functionality with special consideration of cold-set gels derived from heat-denatured whey. Trends Food Sci. Technol. 9:143-151.

Cavella, S., S. Chemin, and P. Masi. 1992. Objective measurement of the stretchability of Mozzarella cheese. J. Text. Stud. 23:185-194.

Chaland, B., F. Mariette, P. Marchal, and J. De Certaines. ${ }^{1} \mathrm{H}$ nuclear magnetic resonance relaxometric characterization of fat and water states in soft and hard cheese. J. Dairy Res. 67:608-618.

Chen, A. H., J. W. Larkin, C. J. Clark, and W. E. Irvine. 1979. Textural analysis of cheese. J. Dairy Sci. 62:901-907.

Creamer, L. K., H. F. Zoers, N. F. Olson, and T. Richardson. 1982. Surface hydrophobicity of $\alpha_{\mathrm{s} 1}$-casein A and B and its implications in cheese structure. J. Dairy Sci. 65:902-906.

Creamer, L. K., and N. F. Olson. 1982. Rheological evaluation of maturing Cheddar cheese. J. Food Sci. 47:632-636, 646.

Dalgleish, D. G. 1993. The enzymatic coagulation of milk. Pages 69100 in Cheese: Chemistry, Physics and Microbiology, 2nd ed. P. F. Fox, ed. Aspen Publishers, Gaithersburg, MD.

De Jong, L. 1976. Protein breakdown in soft cheese and its relation to consistency. 1. Proteolysis and consistency of 'Noordhollandse Meshanger' cheese. Neth. Milk Dairy J. 30:242-253.

Denisov, V. P., K. Venu, J. Peters, H. D. Horlein, and B. Halle. 1997. Orientational disorder and entropy of water in protein cavities. J. Phys. Chem. B. 101:9380-9389.

Dejmek, P. 1987. Dynamic rheology of rennet curd. J. Dairy Sci. 70:1325-1330.

Dickinson, E., D. S. Horne, V. J. Pinfield, and F. A. M. Leermakers. 1997a. Self-consistent-field modelling of casein adsorption. Comparison of results for $\alpha_{\mathrm{s} 1}$-casein and $\beta$-casein. J. Chem. Soc. Faraday Trans. 93:425-432.

Dickinson, E., V. J. Pinfield, D. S. Horne, and F. A. M. Leermakers. 1997b. Self-consistent-field modelling of adsorbed casein. Interaction between two protein-coated surfaces. J. Chem. Soc. Faraday Trans. 93:1785-1790.

Farkye, N. Y., and P. F. Fox. 1990. Observations on plasmin activity in cheese. J. Dairy Res. 57:413-418.

Farrell, H. M., E. D. Wickham, J. J. Unruh, P. X. Qi, and P. D. Hoagland. 2001. Secondary structural studies of bovine caseins: Temperature dependence of $\beta$-casein structure as analyzed by circular dichroism and FTIR spectroscopy and correlation with micellization. Food Hydrocoll. 15:341-354.

Fox, P. F. 1970. Influence of aggregation on the susceptibility of casein to proteolysis. J. Dairy Res. 37:173-180. 
Fox, P. F., J. A. Lucey, and T. M. Cogan. 1990. Glycolysis and related reactions during cheese manufacture and ripening. CRC Crit. Rev. Food Sci. Nutr. 29:237-253.

Fox, P. F., T. P. Guinee, T. M. Cogan, and P. L. H. McSweeney. 2000. Fundamentals of Cheese Science. Aspen, Gaithersburg, MD.

Gagnaire, V., R. Boutrou, and J. Léonil. 2001a. How can the peptides produced from Emmental cheese give some insights on the structural features of the paracasein matrix? Int. Dairy J. 11:449-454.

Gagnaire, V., D. Molle, M. Herrouin, and J. Léonil. 2001b. Peptides identified during Emmental cheese ripening: Origin and proteolytic systems involved. J. Agric. Food Chem. 49:4402-4413.

Geurts, T. G., P. Walstra, and H. Mulder. 1974. Water binding to milk protein, with particular reference to cheese. Neth. Milk Dairy J. 28:46-72.

Green, M. L., and A. S. Grandison. 1993. Secondary (non-enzymatic) phase of rennet coagulation and post-coagulation phenomena. Pages 101-140 in Cheese: Chemistry, Physics and Microbiology. 2nd ed. P. F. Fox, ed. Aspen, Gaithersburg, MD.

Gripon, J. C. 1993. Mould-ripened cheese. Pages 111-136 in Cheese: Chemistry, Physics and Microbiology. 2nd ed. P. F. Fox, ed. Aspen, Gaithersburg, MD.

Grufferty, M. B., and P. F. Fox. 1988. Milk alkaline proteinase. J. Dairy Res. 55:609-630.

Guinee, T. P. 2002. The functionality of cheese as an ingredient: A review. Aust. J. Dairy Technol. 57:79-91.

Guinee, T. P., and D. J. O'Callaghan. 1997. The use of a simple empirical method for objective quantification of the stretchability of cheese on cooked pizza pies. J. Food Eng. 31:147-161.

Guinee, T. P., M. A. E. Auty, and C. Mullins. 1999. Observations on the microstructure and heat-induced changes in the viscoelasticity of commercial cheeses. Aust. J. Dairy Technol. 54:84-89.

Guinee, T. P., M. A. E. Auty, and M. A. Fenelon. 2000. The effect of fat content on the rheology, microstructure and heat-induced functional characteristics of Cheddar cheese. Int. Dairy J. 10:277-288.

Guinee, T. P., E. P. Feeney, M. A. E. Auty, and P. F. Fox. 2002. Effect of $\mathrm{pH}$ and calcium concentration on some textural and functional properties of Mozzarella cheese. J. Dairy Sci. 85:1655-1669.

Guo, M. R., and P. S. Kindstedt. 1995. Age-related changes in the water phase of Mozzarella cheese. J. Dairy Sci. 78:2099-2107.

Guo, M. R., J. A. Gilmore, and P. S. Kindstedt. 1997. Effect of sodium chloride on the serum phase of Mozzarella cheese. J. Dairy Sci. 80:3092-3098.

Harvey, C. D., H. A. Morris, and R. Jenness. 1982. Relation between melting and textural properties of process Cheddar cheese. J. Dairy Sci. 65:2291-2295.

Hassan, A., and J. A. Lucey. 2001. Development of two analytical methods to quantify the concentrations of insoluble and soluble calcium in Cheddar cheese. J. Dairy Sci. 84(Suppl. 1):7. (Abstr.)

Holt, C., and H. Roginski. 2001. Milk proteins: Biological and food aspects of structure and function. Pages 271-334 in Chemical and Functional Properties of Food Proteins. Z. E. Sikorski, ed. Technomic, Lancaster, PA.

Horne, D. S. 1998. Casein interactions: Casting light on the Black Boxes, the structure in dairy products. Int. Dairy J. 8:171-177.

Horne, D. S., J. M. Banks, J. Leaver, and A. J. R. Law. 1994. Dynamic mechanical spectroscopy of cheddar cheese. Pages 507-512 in Cheese Yield and Factors Affecting its Control. Proc. IDF Seminar. International Dairy Federation, Brussels, Belgium.

Horne, D. S., and J. Leaver. 1995. Milk proteins on surfaces. Food Hydrocoll. 9:91-95.

Hyslop, D. 2003. Rennet coagulation of milk. Pages 839-878 in Advanced Dairy Chemistry, Volume 1. Proteins. 3rd ed. P. F. Fox and P. L. H. McSweeney, ed. Aspen, Gaithersburg, MD.

International Dairy Federation. 1991. Rheological and Fracture Properties of Cheese. Bull. IDF No. 268, International Dairy Federation, Brussels, Belgium.

Jack, F. R., A. Paterson, and J. R. Piggott. 1993. Relationships between rheology and composition of Cheddar cheese and texture as perceived by consumers. Int. J. Food Sci. Technol. 28:293-302.

Johnson, M., and B. A. Law. 1999. The origins, development and basic operations of cheesemaking technology. Pages 1-32 in Tech- nology of Cheesemaking. B. A. Law, ed. Sheffield Academic Press, Sheffield, UK.

Johnson, M. E., C. M. Chen, and J. J. Jaeggi. 2001. Effect of rennet coagulation time on composition, yield, and quality of reducedfat Cheddar cheese. J. Dairy Sci. 84:1027-1033.

Keller, B., N. F. Olson, and T. Richardson. 1974. Mineral retention and rheological properties of Mozzarella cheese made by direct acidification. J. Dairy Sci. 57:174-179.

Kindstedt, P. S. 1991. Functional properties of Mozzarella cheese: A review. Cult. Dairy Prod. J. 26(3):27-31.

Kindstedt, P. S. 1993. Effect of manufacturing factors, composition, and proteolysis on the functional characteristics of Mozzarella cheese. Crit. Rev. Food Sci. Nutr. 33:167-187.

Kindstedt, P. S., A. Zielinski, M. Almena-Aliste, and C. Ge. 2001. A post-manufacture method to evaluate the effect of $\mathrm{pH}$ on Mozzarella cheese characteristics. Aust. J. Dairy Technol. 56:202-207.

Kindstedt, P. S., J. K. Rippe, and C. M. Duthie. 1989. Measurement of Mozzarella cheese melting properties by helical viscometry. J. Dairy Sci. 72:3117-3122.

Kuo, M.-I., S. Gunasekaran, M. Johnson, and C. Chen. 2001. Nuclear magnetic resonance study of water mobility in pasta filata and non-pasta filata Mozzarella. J. Dairy Sci. 84:1950-1958.

Lane, C. N., P. F. Fox, D. E. Johnston, and P. L. H. McSweeney. 1997. Contribution of coagulant to proteolysis and textural changes in Cheddar cheese during ripening. Int. Dairy J. 7:453-464.

Lawrence, R. C., and J. Gilles. 1982. Factors that determine the $\mathrm{pH}$ of young Cheddar cheese. N.Z. J. Dairy Sci. Technol. 17:1-14.

Lawrence, R. C., L. K. Creamer, and J. Gilles. 1987. Texture development during cheese ripening. J. Dairy Sci. 70:1748-1760.

Lomholt, S. B., and K. B. Qvist. 1999 The formation of cheese curd. Pages 66-98 in Technology of Cheesemaking. B. A. Law, ed. Sheffield Academic Press, Sheffield, UK.

Lucey, J. A. 2002. Formation and physical properties of milk protein gels. J. Dairy Sci. 85:281-294.

Lucey, J. A., C. Dick, H. Singh, and P. A. Munro. 1997. Dissociation of colloidal calcium-phosphate depleted casein particles as influenced by $\mathrm{pH}$ and concentration of calcium and phosphate. Milchwissenschaft 52:603-606.

Lucey, J. A., C. Gorry, and P. F. Fox. 1993a. Changes in the acidbase buffering curves during ripening of Emmental cheese. Milchwissenschaft 48:183-186.

Lucey, J. A., B. Hauth, C. Gorry, and P. F. Fox. 1993b. The acid-base buffering properties of milk. Milchwissenschaft 48:268-272.

Lucey, J. A., and P. F. Fox. 1993 Importance of calcium and phosphate in cheese manufacture: A review. J. Dairy Sci. 76:1714-1724.

Lucey, J. A., M. Tamehana, H. Singh, and P. A. Munro. 2000. Rheological properties of milk gels formed by a combination of rennet and glucono- $\delta$-lactone. J. Dairy Res. 67:415-427.

Luyten, H., T. van Vliet, and P. Walstra. 1987. Note on the shortness of the consistency of Dutch-type cheese. Neth. Milk Dairy J. $41: 285-288$

Luyten, H., T. van Vliet, and P. Walstra. 1991. Characterization of the consistency of Gouda cheese: Rheological properties. Neth. Milk Dairy J. 45:33-53.

Luyten, H., and T. van Vliet. 1996. Effect of maturation on large deformation and fracture properties of (semi-)hard cheeses. Neth. Milk Dairy J. 50:295-307.

Mariette, F., C. Tellier, G. Brule, and P. Marchal. 1993. Multinuclear NMR study of the $\mathrm{pH}$ dependent water state in skim milk and caseinate solutions. J. Dairy Res. 60:175-188.

McMahon, D. J., R. L. Fife, and C. J. Oberg. 1999. Water partitioning in Mozzarella cheese and its relationship to cheese meltability. J. Dairy Sci. 82:1361-1369.

McMahon, D. J., C. J. Oberg, and W. McManus. 1993. Functionality of Mozzarella cheese. Aust. J. Dairy Technol. 48:99-104.

Metzger, L. E., D. M. Barbano, P. S. Kindstedt, and M. R. Guo. 2001. Effect of milk preacidification on low fat Mozzarella cheese: II. Chemical and functional properties during storage. J. Dairy Sci. 84:1348-1356.

Monib, A. M. M. F. 1962. The calcium-paracaseinate-phosphate complex under conditions similar to those in cheese. Meded. Landbhogesch. Wageningen Nederland 62:1-76. 
Morris, H. A., C. Holt, B. E. Brooker, J. M. Banks, and W. Manson. 1988. Inorganic constituents of cheese: Analysis of juice from a one-month-old Cheddar cheese and the use of light and electron microscopy to characterize the crystalline phases. J. Dairy Res. $55: 255-268$

Mounsey, J. S., and E. D. O'Riordan. 1999. Empirical and dynamic rheological data correlation to characterize melt characteristics of imitation cheese. J. Food Sci. 64:701-703.

Muthukumarappan, K., Y.-C. Wang, and S. Gunasekaran. 1999. Estimating softening point of cheeses. J. Dairy Sci. 82:2280-2286.

Noël, Y., P. Boyaval, A. Thierry, V. Gagnaire, and R. Grappin. 1999. Eye formation and Swiss-type cheeses. Pages 222-250 in Technology of Cheesemaking. B. A. Law, ed. Sheffield Academic Press, Sheffield, UK.

Oberg, C. J., A. Wang, L. V. Moyes, R. J. Brown, and G. H. Richardson. 1991. Effects of proteolytic activity of thermolactic cultures on physical properties of Mozzarella cheese. J. Dairy Sci. 74:389-397.

Olson, N. F., S. Gunasekaran, and D. D. Bogenrief. 1996. Chemical and physical properties of cheese and their interactions. Neth. Milk Dairy J. 50:279-294.

Olson, N. F., and D. D. Bogenrief. 1995. Functionality of Mozzarella and Cheddar cheeses. Pages 81-89 in Proc. 4th Cheese Symposium. T. M. Cogan, P. F. Fox, and R. P. Ross, eds. Teagasc, Fermoy, Ireland.

Park, J., J. R. Rosenau, and M. Peleg. 1984. Comparison of four procedures of cheese meltability evaluation. J. Food Sci. 49:1158$1162,1170$.

Paulson, B. M., D. J. McMahon, and C. J. Oberg. 1998. Influence of sodium chloride on appearance, functionality, and protein arrangements in nonfat Mozzarella cheese. J. Dairy Sci. 81:2053-2064.

Peleg, M. 1980. Theoretical analysis of the relationship between mechanical hardness and its sensory assessment. J. Food Sci. 45:1156-1160.

Prentice, J. H., K. R. Langley, and R. J. Marshall. 1993. Cheese rheology. Pages 303-340 in Cheese: Chemistry, Physics and Microbiology. Vol. 1. P. F. Fox, ed. Elsevier, London.

Ramkumar, C., O. H. Campanella, P. J. Watkinson, R. J. Bennett, and L. K. Creamer. 1998. The effects of $\mathrm{pH}$ and time on rheological changes during early cheese maturation. J. Text. Stud. 29:633644.

Roefs, S. P. F. M., T. van Vliet, H. J. C. M. van den Bijgaart, A. E. A. de Groot-Mostert, and P. Walstra. 1990. Structure of casein gels made by combined acidification and rennet action. Neth. Milk Dairy J. 44:159-188.

Rohm, H., H. Lederer, and W. Ginzinger. 1992. Relationship between rheological properties and composition of Swiss-type cheese. 1. Multiple regression analysis. Lebensm.-Wiss. U.-Technol. 25:253-260.

Rowney, M., P. Roupas, M. W. Hickey, and D. W. Everett. 1999. Factors affecting functionality of Mozzarella cheese. Aust. J. Dairy Technol. 54:94-102.

Ruegg, M., P. Eberhard, L. M. Popplewell, and M. Peleg. 1991. Melting properties of cheese. Pages 36-43 in Rheological and Fracture Properties of Cheese. Bull. IDF No. 268, International Dairy Federation, Brussels, Belgium.

Shalabi, S. I., and P. F. Fox. 1982. Influence of $\mathrm{pH}$ on the rennet coagulation of milk. J. Dairy Res. 49:153-157.

Singh, H., O. J. McCarthy, and J. A. Lucey. 1997. Physico-chemical properties of milk. Pages 469-519 in Advanced Dairy Chemistry, Volume 3. Lactose, Water, Salts and Vitamins. 2nd ed. P. F. Fox, ed. Chapman \& Hall, London.

Srinivasan, M., and J. A. Lucey. 2002. Effects of added plasmin on the formation and rheological properties of rennet-induced skim milk gels. J. Dairy Sci. 85:1070-1078.

Steffe, J. F. 1996. Rheological Methods in Food Process Engineering. 2nd ed. Freeman Press, East Lansing, MI.
Subramanian, R., and S. Gunasekaran. 1997. Small amplitude oscillatory shear studies on Mozzarella cheese. Part II. Relaxation spectrum. J. Text. Stud. 28:643-656.

Syme, C. D., E. W. Blanch, C. Holt, R. Jakes, M. Goedert, L. Hecht, and L. D. Barron. 2002. A Raman optical activity study of rheomorphism in caseins, synucleins and tau-new insights into the structure and behaviour of natively unfolded proteins. Eur. J. Biochem. 269:148-156.

Taneya, S., T. Izutsu, and T. Sone. 1979. Dynamic viscoelasticity of natural cheese and processed cheese. Pages 369-383 in Food Texture and Rheology. P. Sherman, ed. Academic Press, London.

Thierry, A., D. Salvant-Brunard, M.-M. Madec, F. Michel, and J.-L. Maubois. 1998. Affinage de l'emmental: Dynamique des populations bactérienne et évolution de la composition de la phase aquese. Lait 78:521-542.

Tunick, M. H., P. H. Cooke, E. L. Malin, P. W. Smith, and V. H. Holsinger. 1997. Reorganization of casein submicelles in mozzarella cheese during storage. Int. Dairy J. 7:149-155.

Udabage, P., I. R. McKinnon, and M. A. Augustin. 2001. Effects of mineral salts and calcium chelating agents on the gelation of renneted skim milk. J. Dairy Sci. 84:1569-1575.

Ustanol, Z., K. Kawachi, and J. Steffe. 1994. Arnott test correlates with dynamic rheological properties for determining Cheddar cheese meltability. J. Food Sci. 59:970-971.

Van Slyke, L. L., and W. V. Price. 1979. Pages 239-253 in Cheese. 2nd ed. Ridgeview Publ. Company, Reseda, CA.

Van Vliet, T. 1988. Rheological properties of filled gels. Influence of filler matrix interaction. Colloid Polym. Sci. 266:518-524.

Van Vliet, T. 1991a. Inventory of test methods. Pages 16-25 in Rheological and Fracture Properties of Cheese. Bull. IDF No. 268, International Dairy Federation, Brussels, Belgium.

Van Vliet, T. 1991b. Terminology to be used in cheese rheology. Pages 5-15 in Rheological and Fracture Properties of Cheese. Bull. IDF No. 268, International Dairy Federation, Brussels, Belgium.

van Vliet, T. 1999. Factors determining small-deformation behaviour of gels. Pages 307-317 in Food Emulsions and Foams; Interfaces, Interactions and Stability. E. Dickinson and J. M. Rodriguez Patino, ed. Royal Society of Chemistry, Cambridge.

Visser, J. 1991. Factors affecting the rheological and fracture properties of hard and semi-hard cheese. Pages 49-61 in Rheological and Fracture Properties of Cheese. Bull. IDF No. 268, International Dairy Federation, Brussels, Belgium.

Walstra, P., and T. van Vliet. 1982. Rheology of cheese. Pages 2227 in Bull. IDF No. 153, International Dairy Federation, Brussels, Belgium.

Walstra, P., and T. van Vliet. 1986. The physical chemistry of curd making. Neth. Milk Dairy J. 40:241-259.

Walstra, P., and R. Jenness. 1984. Dairy Chemistry and Physics. John Wiley \& Sons, New York.

Wang, Y.-C., K. Muthukumarappan, M. M. Ak, and S. Gunasekaran. 1998. A device for evaluating melt/flow characteristics of cheeses. J. Text. Stud. 29:43-55.

Yun, J. J., L. J. Kiely, P. S. Kindstedt, and D.M. Barbano. 1993. Mozzarella cheese: Impact of coagulant type on functional properties. J. Dairy Sci. 76:3657-3663.

Yun, J. J., D. M. Barbano, P. S. Kindstedt, and K. L. Larose. 1995. Mozzarella cheese: impact of whey $\mathrm{pH}$ at draining on chemical, composition, proteolysis, and functional properties. J. Dairy Sci. $78: 1-7$.

Zoon, P., and D. Allersma. 1996. Eye and crack formation in cheese by carbon dioxide from decarboxylation of glutamic acid. Neth. Milk Dairy J. 50:309-318.

Zoon, P., T. van Vliet, and P. Walstra. 1988a. Rheological properties of rennet-induced skim milk gels. 1. Introduction. Neth. Milk Dairy J. 42:249-269.

Zoon, P., T. van Vliet, and P. Walstra. 1988b. Rheological properties of rennet-induced skim milk gels. 2 . The effect of temperature. Neth. Milk Dairy J. 42:271-294. 